\title{
LA FINANCIACIÓN DEL DÉFICIT DEL GOBIERNO CENTRAL: SUS COSTOS ECONÓMICOS Y LA INDEPENDENCIA DEL BANCO CENTRAL EN COLOMBIA DESDE 1991*
}

\author{
JAIRO PARADA CORRALES** \\ CRISTINA ALBOR CEPEDA***
}

Recibido 27 de Julio de 2011 / Enviado para Modificación 9 de Noviembre de 2011/ Aceptado 30 de Noviembre de 2011

\section{RESUMEN}

Las finanzas del Gobierno Nacional Central de Colombia desde 1991 reflejan un patrón explosivo en el crecimiento de la carga de intereses de la deuda sobre el PIB, alcanzando niveles superiores al 4\% Este comportamiento está estrechamente relacionado con la política de endeudamiento basada en las colocaciones de títulos de deuda en el mercado financiero a tasas oligopsónicas fijadas por el grupo de bancos compradores denominado Creadores de mercado. El presente trabajo va dirigido a establecer los efectos macroeconómicos de la reorientación de la política financiera de los déficits del gobierno central colombianos desde 1991, indagando a nivel teórico, institucional y empírico en las causas del crecimiento explosivo de la deuda pública interna observado desde que la Constitución de 1991, inspirada en los preceptos ortodoxos del Consenso de Washington y del Nuevo Consenso en Macroeconomía. Dichos preceptos privilegiaron la inflación objetivo y la imposibilidad de la emisión monetaria como una alternativa más económica para el financiamiento del gobierno central, lo cual obligó al Gobierno a acudir a recursos en el mercado financiero interno a costos económicos y sociales superiores a los incurridos en décadas precedentes.

Palabras clave: Finanzas Públicas, Política Fiscal, Déficit Fiscal, Deuda Pública, Colombia.

\section{Clasificación JEL: E52, E58, H62, H63}

\footnotetext{
* Este trabajo es una versión modificada de un trabajo de investigación como proyecto de menor cuantía financiado por la Universidad del Norte. Fue presentado en el I Seminario Internacional de Economía Postkeynesiana y Heterodoxa, realizado en la Universidad Nacional de Colombia, del 10 al 12 de Agosto del 2010 en Bogotá.

**Jairo Parada Corrales. Profesor del Departamento de Economía del Instituto de Estudios Económicos del Caribe (IEEC) de la Universidad del Norte. Barranquilla. Colombia. Correo electrónico: jparadac@uninorte.edu.co.

***Cristina Albor. Economista del Instituto de Estudios Económicos del Caribe-Universidad del Norte. Correo electrónico: calbor@uninorte.edu.co.
} 


\begin{abstract}
Since 1991, public finance of the Colombian Central Government reveals an explosive pattern in the burden in terms of GDP of interest payments of public debt, reaching levels over $4 \%$. This behavior is deeply connected with a debt financing public policy based on issuing public debt in the private financial market subjected to oligopolistic rates determined by a small group of financial agents that are price makers. This work is oriented to establish the macroeconomic effects of the reorientation of public debt financing policy in Colombia since the Constitution of 1991 was implemented, developing a theoretical, institutional and empirical inquiry regarding the causes of the explosive growth of the domestic public debt observed, based on orthodox recommendations inspired on the Washington consensus and the so called new consensus in Macroeconomics. These assumptions privileged inflation targeting and the almost absolute impossibility of using primary emission as a less expensive central government deficit financing, which forced the government to lend in private financial markets with higher social and economic costs compared with the same variables in previous decades.
\end{abstract}

Key words: Public finance, fiscal policy, public debt, Colombia

JEL Classification: E52, E58, H62, H63

\title{
INTRODUCCIÓN
}

El presente trabajo va dirigido a establecer los efectos macroeconómicos de la reorientación de la política financiera de los déficits del gobierno central colombianos desde 1991, indagando a nivel teórico y empírico en las causas del crecimiento explosivo de la deuda pública interna observado desde que la Constitución sancionó la emisión monetaria como una alternativa para el financiamiento del gobierno central que obligó a acudir a los recursos en el mercado financiero interno. Se pretende analizar en detalle la relación existente entre la evolución del déficit fiscal y sus diversas fuentes de financiamiento y especialmente los efectos causados por el uso del financiamiento mediante emisiones de Títulos de Tesorería TES.

Lograr una aproximación a tales efectos requiere de seguir determinados pasos. El primero es establecer un marco teórico en el cual se sustentan las ideas heterodoxas del uso del déficit fiscal como instrumento anticíclico, del papel de las bajas tasas de interés como emisores de señales optimistas 
a los agentes y de la importancia de la coordinación entre las políticas fiscal y monetaria para lograr una política macroeconómica eficiente basada más que en la estabilidad de precios en la estabilidad macroeconómica referida no solo a la tasa de inflación, sino también a la tasa de desempleo. Este marco teórico se brinda en el apartado 2.

El siguiente paso es hacer una descripción paralela de dos periodos de la historia económica caracterizados por distintas estructuras de prestamistas del Estado a fin de establecer las diferencias en las variables que definen el endeudamiento entre uno y otro periodo. En este caso se expone un periodo de financiamiento fuertemente monetario apoyado en el Banco Central como es la década de los ochentas en contraste con el financiamiento vía mercado que se experimenta a partir de los noventas. Como parte de este apartado se obtendrá una evaluación empírica de la condición neoclásica para el equilibrio fiscal describiendo sus principales limitaciones y se analizaran las causas de los resultados obtenidos, lo cual será el contenido del apartado 3. Las conclusiones más importantes serán presentadas en el apartado 4.

\section{ANTECEDENTES TEÓRICOS}

De los debates sobre la combinación de estrategias monetarias y fiscales se ha concebido como ampliamente aceptable el Nuevo Consenso (NC) macroeconómico de orientación política, el cual está compuesto de una descripción del proceso generador de ingreso - una curva IS-, una descripción del proceso de inflación -curva de Phillips en versión aceleracionista- y la especificación de una regla para la conducción de la política monetaria- Regla de Taylor-. Aparte de la política monetaria ninguna otra intervención de política juega un papel importante, dando origen a lo que Rochon y Stterfield (2007, citado por Cordero, 2008 (1)) llaman "dominancia de la política monetaria". Dentro del nuevo consenso el objetivo último de la política monetaria es establecer la tasa de inflación de equilibrio y la mejor forma de lograrlo es delegando la defensa de la estabilidad de precios en un Banco Central independiente de la injerencia del ejecutivo, cuya variable operativa es la tasa de interés.

La posición teórica que adoptaremos para el desarrollo de este trabajo toma como punto de partida la teoría de Keynes de la preferencia por la liquidez y los posteriores desarrollos postkeynesianos. Dentro de una política keynesiana pura el principal propósito es el manejo de la tasa de 
interés. La más importante innovación teórica de Keynes, la teoría de la preferencia por la liquidez, demostró que la recompensa por renunciar a la liquidez dependía en gran medida de las expectativas, las cuales podían ser manejadas por las autoridades. Keynes sostuvo que: "La tasa corriente de interés depende, (...) no de la fuerza del deseo de mantener riqueza, sino en las fuerzas del deseo de mantener ésta en una forma líquida e ilíquida respectivamente, junto con la cantidad de la oferta de riqueza en una forma relativa a la oferta de ésta en la otra forma". (Keynes (2), citado en Tily, (3)).

La teoría de Keynes y el enfoque post-keynesiano no recomiendan la utilización de la tasa de interés como instrumento para mantener el control de la inflación, puesto que en la mayoría de casos, la inflación se identifica como un problema del lado de la oferta, mientras la tasa de interés actúa a través de la demanda. La idea post-keynesiana es que una elevación de la tasa de interés ataca los síntomas de la inflación y no sus causas, y que existen diferentes tipos de inflación y para cada uno de ellos debe utilizarse un instrumento de control diferente (4).

La experiencia de Keynes (5) en el campo de la política fiscal le llevó a utilizar la preferencia por la liquidez para desarrollar una teoría completa y formal del manejo de la deuda en conjunto con la política monetaria, cuyo principal supuesto deriva del concepto de economía monetaria de Keynes.

El principio básico de política monetaria en Keynes establece que es más importante fijar la tasa de descuento en línea con el amplio espectro de tasas que las autoridades buscan establecer que reservar su uso para el control de crédito de corto plazo (3). Desde la perspectiva teórica general, el banco central usa su monopolio sobre la emisión del efectivo para fijar las tasas a través de arreglos de descuento. Ciertos activos elegibles, tradicionalmente deuda del gobierno de corto plazo se reservan en el banco central en cambio de efectivo a la tasa de descuento requerida. Como lo observó Keynes en el Tratado sobre el dinero "es característico de los sistemas modernos que el banco central está listo para comprar por dinero a una tasa de descuento estipulada cualquier cantidad de bonos de ciertos tipos aprobados". En este sentido el banco central ofrece liquidez o dinero en la forma de efectivo con el fin de manejar la tasa de interés que apuntala al préstamo bancario de corto plazo.

Keynes reconoció que debido a los rendimientos decrecientes del capital el rendimiento del gasto agregado en capital disminuiría a través del 
tiempo, por lo que, con la tasa de interés gobernando el volumen de gasto de capital, una política monetaria enfocada a un nivel de empleo alto y estable debía entonces manejarse a tasas de interés no solo bajas sino decrecientes. La relevancia de los rendimientos decrecientes de capital como un componente del aparato para una política monetaria "barata" está en su papel en la generación de expectativas. Con el reconocimiento de que la tasa de interés de largo plazo se movería en línea con el rendimiento del capital, el público entendería que los futuros movimientos en la tasa de interés de largo plazo solo estarían en la dirección de la disminución. (3).

Desde la perspectiva del manejo de la deuda pública esto significa que los términos de los bonos de largo plazo no deben ser sustituidos por términos equivalentes en una emisión posterior. Es deseable de esta manera prevenir, en la medida de lo posible, la situación en la que previos bonos con altos intereses permanecen en el mercado en la medida en que nuevos bonos con menores intereses se van emitiendo (3).

Finalmente, se ha considerado que la reducción y estabilización de la inflación a nivel internacional que se ha logrado presuntamente gracias a la independencia de la mayor parte de Bancos Centrales son muestra de la eficiencia con que actúa esta política. Sin embargo, esta noción es aceptable solo si se entiende como eficiencia el logro cabal de un nivel inflacionario objetivo. No obstante, adoptaremos la definición de Sicsú (6) según la cual la noción de eficiencia no se refiere exclusivamente a alcanzar un objetivo, pues es indispensable que la evaluación de una política lleve en consideración sus costos de implementación y los efectos colaterales producidos ${ }^{1}$. Objetivos ambiguos, instrumentos en conflicto y elevación de la incertidumbre caracterizan una política ineficiente que no alcanzará sus metas y/o producirá efectos colaterales dañinos. Veremos cómo este es el caso cuando existe liderazgo de la política monetaria.

\footnotetext{
${ }^{1}$ Una política económica eficiente es aquella que 1) Persigue un objetivo prioritario, 2) crea un mínimo de utilización contradictoria entre sus instrumentos y 3) emite un máximo de señales a los agentes a fin de estimularlos a actuar con el mínimo de incertidumbre con relación al futuro en la misma dirección señalada por las autoridades. Cuánto más claras sean estas señales mayor será el estímulo privado y menor será la intensidad y/o tiempo de utilización de los instrumentos fiscales y monetarios.
} 


\section{ESTRUCTURA FINANCIERA DEL GOBIERNO NACIONAL CENTRAL}

\section{La estructura del financiamiento del GNC en los ochentas.}

Desde 1980 hasta 1984 se presenta una considerable expansión del déficit del gobierno central como resultado tanto de un ritmo negativo de crecimiento de los ingresos como de un mayor crecimiento del gasto. Mientras los primeros decrecen anualmente como proporción del PIB un promedio anual de $-8,2 \%$ los últimos se incrementan en un $4,5 \%$. Este periodo se caracterizó por el surgimiento de una crisis de deuda externa a nivel Latinoamericano que condujo al cierre de los mercados internacionales de crédito y a la adopción de severas políticas de ajuste.

Las finanzas del Gobierno Central evidenciaron una crisis financiera de grandes proporciones la cual condujo al aumento del déficit promedio a niveles cercanos al 3,5\% del PIB. Si bien las utilidades de la Cuenta Especial de Cambios (CEC) continuaron representando las principales fuentes de financiamiento, el crédito del Banco de la República y el endeudamiento interno por medio de títulos adquirieron una mayor importancia. Destaca la colocación de Títulos de Ahorro Nacional (TAN) en el mercado de capitales doméstico.

Entre 1986 y 1990 se observa una reducción significativa del tamaño del déficit, el cual desciende a un nivel promedio anual de 1,1\% del PIB, gracias al proceso de ajuste fiscal adoptado dentro del marco de la crisis de la deuda externa y la decisión de incluir dentro de los objetivos de la política económica la estabilidad financiera del gobierno y del sector público en su conjunto. Para este periodo se evidencia ya una rápida reducción del financiamiento otorgado por el Banco de la República y el aumento de la financiación interna, la cual alcanzó un nivel promedio sin precedentes de $0,5 \%$ del PIB (7).

Para el total de la década de los 80 s tenemos que, en general, durante todos los años que abarca este periodo, se presenta un continuo déficit fiscal que asciende desde \$31,2 mil millones en 1980 hasta \$250,4 mil millones en 1989 con una considerable reducción en 1987. El Saldo total de la deuda se ubica en $\$ 134$ mil millones al comenzar la década y alcanza una cifra de $\$ 3,05$ billones en el último año, creciendo a un promedio anual de $42 \%$ y del 10,7\% como porcentaje del PIB. La mayor parte del periodo prevalece el endeudamiento externo, ubicándose entre el 51,2\% (1984) y el 84,2\% (1981). El endeudamiento externo crece a una tasa promedio anual del $9,3 \%$ mientras el interno se acelera creciendo al $23 \%$ en promedio. 
TABLA 1. INGRESOS, GASTOS Y ENDEUDAMIENTO DEL GNC. 1980-1989.

\begin{tabular}{|c|c|c|c|c|c|c|c|c|}
\hline años & Ingresos & Gastos & Déficit & $\begin{array}{c}\text { Deuda } \\
\text { Externa }\end{array}$ & $\begin{array}{l}\text { Deuda } \\
\text { Interna }\end{array}$ & $\begin{array}{c}\text { Deuda } \\
\text { Total }\end{array}$ & $\% D E$ & $\% D I$ \\
\hline 1980 & 132,00 & 163,20 & 31,20 & 106,38 & 27,66 & 134,05 & 79,4 & 20,6 \\
\hline 1981 & 156,70 & 214,90 & 58,20 & 149,70 & 28,11 & 177,81 & 84,2 & 15,8 \\
\hline 1982 & 189,70 & 291,10 & 101,40 & 196,67 & 39,95 & 236,62 & 83,1 & 16,9 \\
\hline 1983 & 237,50 & 344,60 & 107,10 & 235,17 & 104,16 & 339,32 & 69,3 & 30,7 \\
\hline 1984 & 302,80 & 474,20 & 171,40 & 303,02 & 288,69 & 591,72 & 51,2 & 48,8 \\
\hline 1985 & 447,80 & 578,30 & 130,50 & 508,52 & 440,32 & 948,84 & 53,6 & 46,4 \\
\hline 1986 & 640,50 & 745,50 & 105,00 & 931,85 & 597,80 & $1.529,65$ & 60,9 & 39,1 \\
\hline 1987 & 935,30 & 977,00 & 41,70 & $1.194,55$ & 703,01 & $1.897,56$ & 63,0 & 37,0 \\
\hline 1988 & $1.210,20$ & $1.380,60$ & 170,40 & $1.633,30$ & 805,91 & $2.439,21$ & 67,0 & 33,0 \\
\hline 1989 & $1.536,10$ & $1.786,50$ & 250,40 & $2.152,85$ & 853,14 & $3.005,99$ & 71,6 & 28,4 \\
\hline
\end{tabular}

Fuente: Elaboración propia con base en: Ingresos, gastos y déficit: Banco de la República.(2009) Deuda total, externa e interna: Contraloría General de la República. (2009) Cifras en miles de millones de pesos.

El trabajo de Villamizar (2003) resalta la relevancia de la estructura financiera de los años 80s como factor determinante delos mejores resultados obtenidos por Colombia durante los años del estrangulamiento externo. Según varios indicadores de crédito del Banco de la República al Gobierno se evidencia una considerable ampliación de la liquidez con destino al sector público en los primeros años de la década de los 80s hasta 1984, año en que la crisis de la deuda de América Latina se manifestó con toda su fuerza.

Así, por ejemplo, el crecimiento del crédito neto real al gobierno a precios de 1979 superó el 100\% en 1981 y 1982 y el 28\% en los dos años siguientes. En términos del PIB, el saldo de dicho crédito pasó del 1.6\% en 1980 al $3.7 \%, 7.5 \%, 9.4 \%$ y $11.3 \%$ en los años 1981 a 1984 respectivamente. Como porcentaje de los ingresos corrientes del gobierno, a su vez, el flujo de estos recursos al gobierno representó porcentajes superiores al $30 \%$ en estos años, alcanzando un $60 \%$ en 1982 y casi un $50 \%$ en 1984 . Con relación a los cambios en la oferta monetaria dichos créditos representaron más del 100\% de M1 en estos años. (Villamizar, 2003).

En los años 1980s la utilización de bonos para financiar apropiaciones del gasto fue prácticamente inexistente. La mayor parte de éstos fueron bonos sectoriales utilizados especialmente para la agricultura y la seguridad, los cuales perdieron participación rápidamente entre 1980 y 1985 debido a que la bonanza de divisas favoreció la Cuenta Especial de Cambios. Además, el acceso a estos recursos se vio contrarrestado por la imposición de los Títulos de Ahorro Nacional, los cuales fueron la punta de lanza de una estrategia impulsada por el Estado, supuestamente para deprimir las presiones inflacionarias causadas por la excesiva emisión. 
TABLA 2. CRÉDITO DEL BANCO DE LA REPÚBLICA AL GOBIERNO NACIONAL CENTRAL. 1979-1989

\begin{tabular}{|c|c|c|c|c|c|c|}
\hline & Crédito Bruto & $\begin{array}{l}\text { Disponibili- } \\
\text { dades }\end{array}$ & Crédito Neto & $\begin{array}{c}\text { Cuenta } \\
\text { Especial de } \\
\text { Cambios }\end{array}$ & $\begin{array}{c}\text { Crédito Bruto } \\
\text { ajustado por } \\
\text { CEC }\end{array}$ & $\begin{array}{c}\text { Crédito Neto } \\
\text { ajustado por } \\
\text { CEC }\end{array}$ \\
\hline 1979 & 6.828 & 14.184 & -7.356 & 21.265 & 28.093 & 13.909 \\
\hline 1980 & 7.540 & 19.802 & -12.262 & 32.576 & 40.116 & 20.314 \\
\hline 1981 & 5.705 & 16.078 & -10.373 & 56.073 & 61.778 & 45.700 \\
\hline 1982 & 20.542 & 5.437 & 15.104 & 79.522 & 100.063 & 94.626 \\
\hline 1983 & 44.373 & 10.947 & 33.426 & 91.604 & 135.977 & 125.030 \\
\hline 1984 & 90.010 & 9.066 & 80.944 & 79.204 & 169.213 & 160.147 \\
\hline 1985 & 89.275 & 15.705 & 73.570 & 64.672 & 153.947 & 138.242 \\
\hline 1986 & 96.425 & 48.392 & 48.033 & 50.894 & 147.319 & 98.927 \\
\hline 1987 & 87.676 & 36.574 & 51.102 & 40.624 & 128.300 & 91.727 \\
\hline 1988 & 77.302 & 39.261 & 38.041 & 31.706 & 109.009 & 69.748 \\
\hline 1989 & 61.224 & 29.804 & 31.420 & 34.717 & 95.941 & 66.137 \\
\hline
\end{tabular}

Fuente: Villamizar (2003). Pp84. Miles de Millones de pesos de 1979.

TABLA 3. CRÉDITO DEL BANCO DE LA REPÚBLICA AL GOBIERNO NACIONAL Y SU RELACIÓN CON ALGUNAS VARIABLES MACROECONÓMICAS.

\begin{tabular}{|c|c|c|c|c|}
\hline & $\begin{array}{c}\text { Crecimiento real del } \\
\text { crédito neto ajustado } \\
\text { por CEC }\end{array}$ & $\begin{array}{c}\text { Saldo del crédito neto } \\
\text { ajustado como \% del } \\
\text { PIB }\end{array}$ & $\begin{array}{c}\text { Flujo crédito neto } \\
\text { ajustado como \% de } \\
\text { ingresos corrientes } \\
\text { del gobierno }\end{array}$ & $\begin{array}{c}\text { Flujo crédito neto } \\
\text { ajustado como \% de } \\
\text { cambio en M1 }\end{array}$ \\
\hline 1979 & 1.2 & 8.8 & 23.8 \\
\hline 1980 & 46 & 1.6 & 30 & 109.5 \\
\hline 1981 & 125 & 3.7 & 60.1 & 172.8 \\
\hline 1982 & 107.1 & 7.5 & 42.4 & 125.6 \\
\hline 1983 & 32.1 & 9.4 & 48.2 & 156.1 \\
\hline 1984 & 28.1 & 11.3 & 5.6 & 17.7 \\
\hline 1985 & -13.7 & 9.3 & -9.8 & -42.4 \\
\hline 1986 & -28.4 & 5.9 & 6.7 & 13 \\
\hline 1987 & -7.3 & 5.2 & -1 & -4.4 \\
\hline 1988 & -24 & 3.8 & 5.7 & 26.4 \\
\hline 1989 & -5.2 & 3.5 & & \\
\hline
\end{tabular}

Fuente: Villamizar (2003). pp85

\section{Estructura del endeudamiento del gobierno nacional central desde 1990.}

Según cifras de la Contraloría General de la República, el endeudamiento total del Gobierno Nacional Central colombiano ascendió al valor de $\$ 205,57$ billones en el año 2010, presentando un crecimiento del 7,8\% con respecto a su valor en el año 2009 ( $\$ 190,54$ billones). A lo largo de la década de los años 90, el saldo total de la deuda del gobierno como porcentaje 
del tamaño de la economía registra cifras entre el 14,5\% (\$3,9billones) en 1990 y el 23,4\% (\$44,9billones) en 1999, creciendo a un promedio del 6,5\% anual.

La década que abarca los años 2000 a 2010 inició con un saldo total de la deuda de $\$ 67,8$ billones registrado en el año $2000,51.1 \%$ mayor a su valor en 1999. Ésta década evidenció una paulatina disminución en el ritmo del endeudamiento del Gobierno, lo cual se refleja en una tasa anual de crecimiento promedio en esta variable de 5,3\%. La década finaliza con un saldo total de $\$ 205,57$ billones en 2010 que representa el 37,5\% del PIB de este mismo año, mientras ese mismo porcentaje fue de $34,5 \%$ al iniciarse la década. Esto quiere decir que si bien el ritmo de endeudamiento se ha venido reduciendo, en términos absolutos, aún se mantiene en niveles más altos que los del inicio de década.

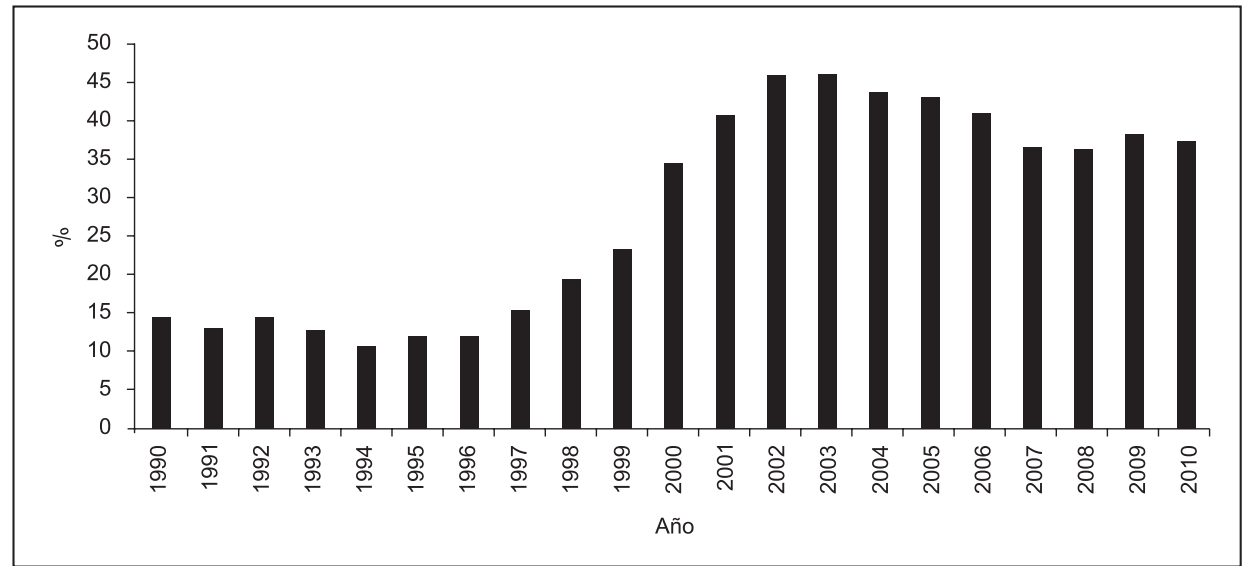

Fuentes: Elaboración propia con base en: Banco de la República- Deuda del GNC. PIB base 2000- Contraloría General de la República (2010).

La característica más notable del endeudamiento total del Estado se evidencia en su composición entre fuentes internas y externas de financiamiento. Mientras al inicio de la década de 1990s la composición de ésta entre deuda interna y deuda externa era del 13\% y $87 \%$ respectivamente, al finalizar la década esta composición se encontraba prácticamente equilibrada en $49 \%$ y $51 \%$ y ya en el año 2010 los porcentajes respectivos fueron de $71 \%$ y $28 \%$. 
GRÁFICO 2. COMPOSICIÓN DEL SALDO DE LA DEUDA

ENTRE INTERNA Y EXTERNA 1990-2010

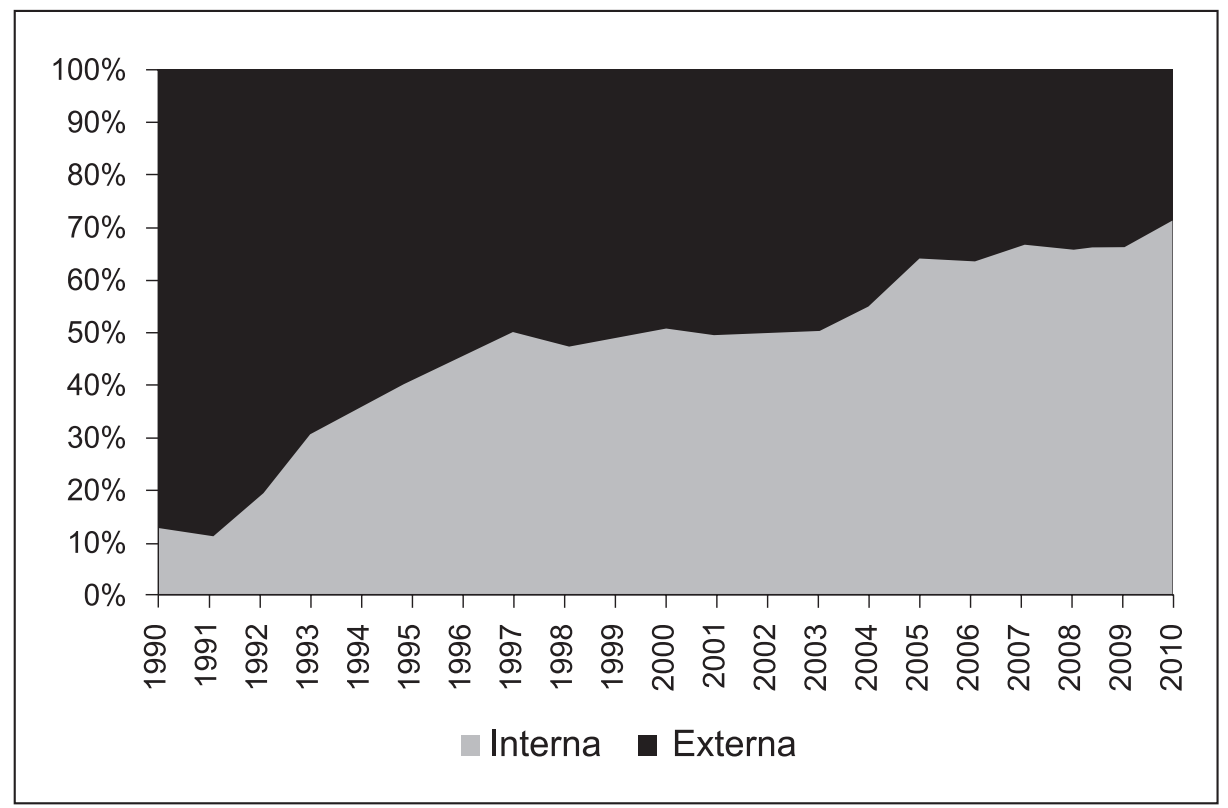

Fuente: Elaboración propia con base en Contraloría General de la República.

\section{COMPONENTES DEL ENDEUDAMIENTO TOTAL DEL GNC}

\section{- El Déficit Total}

En términos absolutos, el déficit del GNC en 2010 ascendió al valor de $\$ 19,2$ billones, después de mantenerse a lo largo de la primera década del siglo XXI en un promedio de $\$ 12$ billones, donde los puntos máximo y mínimo fueron, respectivamente, 2010 (\$19,2 billones) y 2008 (\$8,46 billones). En la década anterior los valores registrados del déficit fueron de \$180,1 mil millones en 1990 ascendiendo hasta $\$ 8,9$ billones en 1999, siendo el punto mínimo 1991 con $\$ 67,8$ mil millones.

Como porcentaje del PIB el déficit total incluido el pago de intereses ha sido positivo a lo largo de las dos últimas décadas, asciendo desde el 0,75\% del PIB en 1990 hasta el 3,52 \% en 2010alcanzando los mayores niveles entre 1999 y 2001 (5\%), disminuyendo continuamente entre 2002 y 2008 (4,5\% y 1,7\%) con excepción del año 2005 (4,2\%). 


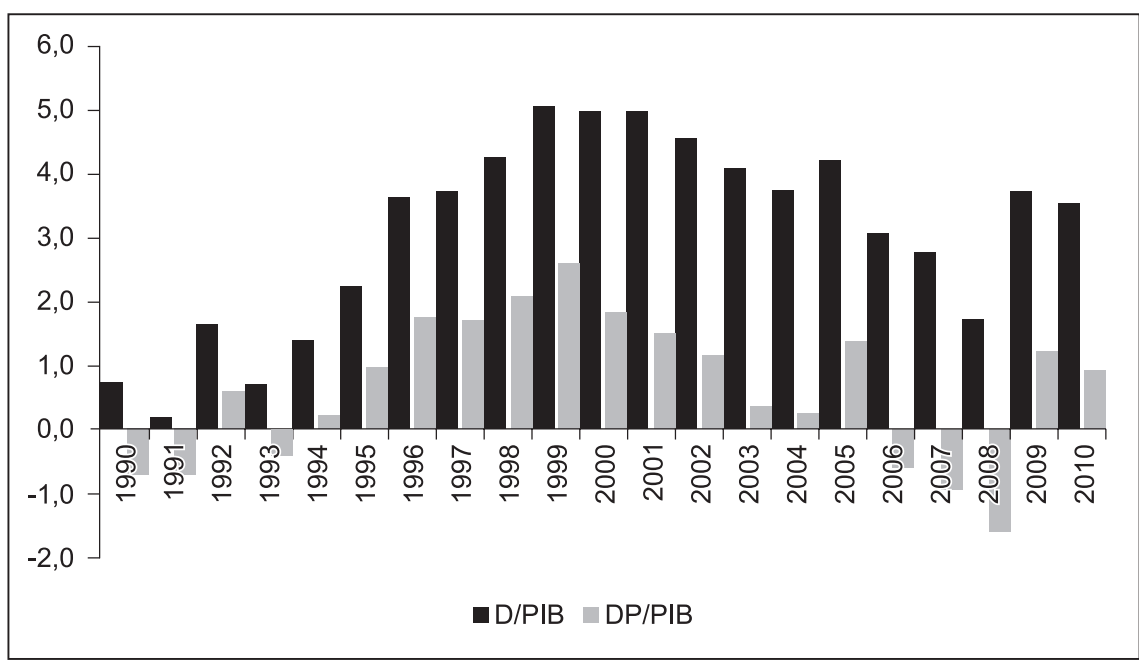

Fuente: Elaboración propia con base en: Banco de la República.

\section{- El Déficit Primario}

En el componente primario del déficit ambos elementos, ingreso y gasto primario, destacan por la reducción en sus ritmos de crecimiento entre ambos periodos. El crecimiento promedio de los ingresos para el total de la década de los noventas es del $29,8 \%$. Por el lado del ingreso tenemos que los años 1990 comienzan con un crecimiento porcentual del 36\% en 1990 que disminuye hasta el $20 \%$ en 1999, obteniéndose un nivel record en 1991 del 51,5\% y un nivel mínimo en 1998 de tan solo 10\%.

El crecimiento promedio del gasto primario a lo largo de los noventas registra un 31,8\% anual, 2 puntos por encima del crecimiento del ingreso. La década empieza con una tasa de crecimiento del gasto de $26,9 \%$ en 1990 alcanzando rápidamente un máximo del 55,2\% en 1992 y finalmente disminuyendo con la misma velocidad hasta el 14\% en 1998.

En la década del año 2000 al 2010, mientras la tendencia en el crecimiento de los ingresos se mantiene relativamente estable alrededor del $13 \%$ anual, con excepciones en los años 2009 y 2010 ( $2 \%$ y -3,9\%, respectivamente), en materia de gastos primarios la tendencia es más inestable teniendo que 2001 y 2005 registran las mayores tasas (20,2\% y 21,5\%), 2002 y 2003 las menores (6,5\% y 8,2\%). Al igual que en el caso del ingreso, la década finaliza con una fuerte caída del gasto primario entre 2006 y 2010 desde el $10,1 \%$ al $2,7 \%$, respectivamente. 
Considerando en conjunto el déficit primario como porcentaje del PIB vemos un continuo crecimiento entre 1991 y 1999, después de lo cual inicia una tendencia contraria hacia la reducción con un ligero repunte en 2005 y nuevamente en 2009 y 2010, a una tasa de crecimiento mayor. Mientras el déficit total ha sido positivo a lo largo de los últimos 20 años, por el lado del déficit primario existen para el periodo considerado varios años con resultados superavitarios.

\section{- Los Intereses de la Deuda}

En valores absolutos el saldo de intereses de la deuda durante las dos últimas décadas asciende desde $\$ 262,4$ mil millones en 1990 hasta $\$ 14,2$ billones en 2010, creciendo aceleradamente en la década de los 1990 a una tasa promedio anual de 38,9\%, mientras en la última década este ritmo de crecimiento anual se reduce hasta un $10,8 \%$ en promedio.

En relación con el PIB en 1990 la carga de intereses representa una tasa de $1,09 \%$ y al finalizar la década esta se triplica hasta registrar un 3,32\%, cifra que aumenta hasta el 4,5\% en 2003 y se mantiene considerablemente estable alrededor del 4,2\% con la excepción del año 2010, donde factores como el crecimiento económico, el efecto de la baja de la tasa de interés y las operaciones de canje, contribuyeron con una reducción de esta relación a un estimado de 3\% del PIB, según informe de la Contraloría General año 2010.

La carga total de intereses incluye tanto aquellos resultantes del endeudamiento externo como los del endeudamiento interno. El primero está determinado por todos los factores que afectan las tasas de interés externas y las variaciones de la tasa de cambio mientras en el caso interno este está determinado por todos los factores que influyen en las tasas de interés internas de la deuda. 


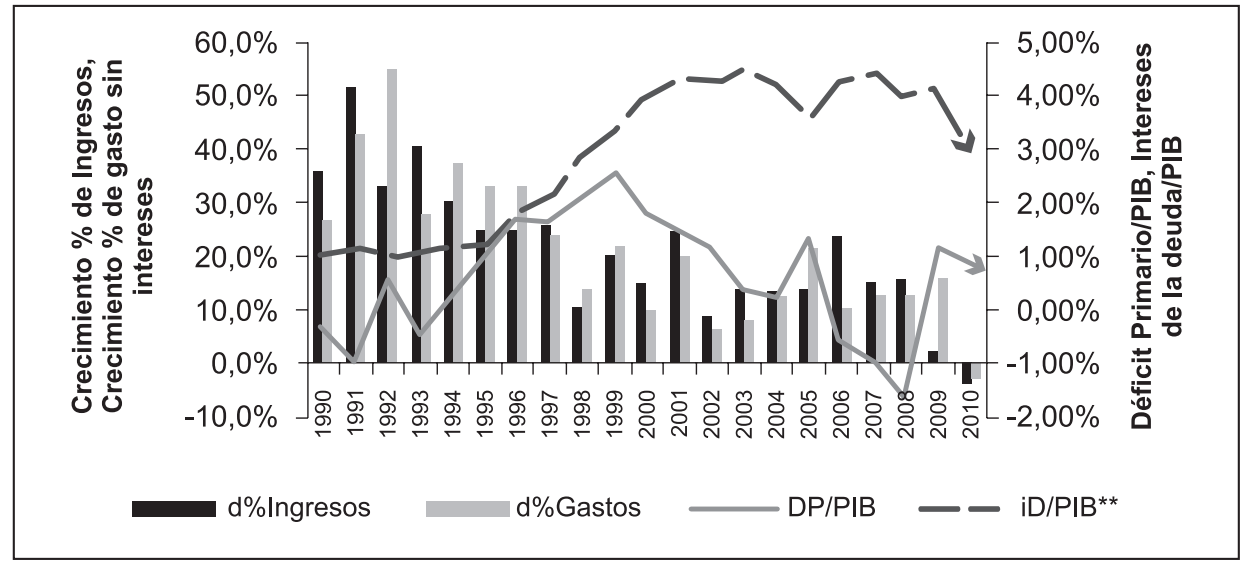

Fuente: Elaboración propia con base en: Banco de la República.

${ }^{* *}$ Estimado según informe de la Contraloría General (2010).

\section{COMPOSICIÓN DEL PAGO DE INTERESES DE LA DEUDA INTERNA}

La información sobre pagos de intereses sobre la deuda interna del gobierno proviene de Contraloría General de la República y se encuentra disponible únicamente para los años de 1992 a 2006. Tenemos para el año 1992 un pago total de intereses de $\$ 133.138$ millones de pesos, un gran porcentaje representado por títulos de ahorro nacional y títulos de Tesorería TES A, de los bonos de Ley 85 de 1985, y de bonos sectoriales educativos y agrarios. Los títulos de Tesorería TES B, los cuales son el instrumento con el que actualmente se realizan casi la totalidad de operaciones de financiamiento interno apenas participaron con el 0,7\% del total de pagos de intereses en este año.

Ya en 1999 al finalizar la década, el 94\% del pago de intereses de deuda interna del gobierno nacional corresponden a intereses de los TES B. El pago total por intereses para este año registro $\$ 3,73$ billones de pesos, $\$ 3,53$ billones correspondientes a pagos por intereses de estos títulos. El último año del periodo, 2006 el pago total de intereses asciende a $\$ 10,11$ billones, 98,4\% (\$9,95 billones) correspondientes a TES B. Existen entonces dos componentes que explican casi la totalidad de los pagos de intereses de deuda interna: la tasa de interés pagada por estos títulos y la estructura a plazos a la cual se realizan las colocaciones. Analicemos esto posteriormente. 


\section{PRESTAMISTA 1992-1999.}

\begin{tabular}{|c|c|c|c|c|c|c|c|c|}
\hline FUENTE & 1992 & 1993 & 1994 & 1995 & 1996 & 1997 & 1998 & 1999 \\
\hline Bonos nal. Deuda interna Ley 21/63 & 3.882 & 4.852 & 3.368 & 3.235 & 2.402 & 2.233 & 1.721 & 1.675 \\
\hline Títulos de ahorro nacional TAN & 32.864 & 2.878 & - & - & - & - & 151 & - \\
\hline Títulos de Tesorería TES B & 877 & 41.872 & 236.104 & 543.241 & 1.291 .394 & 1.776 .200 & 2.564 .370 & 3.509 .923 \\
\hline Títulos de Tesorería TES A & 14.525 & 112.528 & - & - & 110.475 & 82.595 & 68.279 & 55.469 \\
\hline Títulos de Tesorería TES B - Dólares & - & - & - & - & - & - & - & 29.874 \\
\hline Bonso para la seguridad & - & - & - & - & - & - & 57.664 & 38.089 \\
\hline B V C universidades & - & - & - & - & - & - & 30.261 & 7.743 \\
\hline Bonos de solidaridad para la paz & - & - & - & - & - & - & - & - \\
\hline Títulos de Tesorería TES B - UVR & - & - & - & - & - & - & - & - \\
\hline Títulos de Reducción de Deuda TRD & - & - & - & - & - & - & - & - \\
\hline Títulos de tesorería TES Ley 546 & - & - & - & - & - & - & - & - \\
\hline Títulos de tesorería TES - Corto plazo & - & - & - & - & - & - & - & - \\
\hline Bonos educativos valor constante & 42.067 & 34.591 & 38.591 & 29.616 & 24.109 & 17.016 & 17.381 & 6.875 \\
\hline Bonos Ley 55 de 1985 & 16.605 & 35.752 & 40.648 & - & - & - & - & \\
\hline Bonos Ley 55 de 1985 & - & - & - & 19.913 & 23.925 & 27.332 & - & - \\
\hline TITULOS DE TESORERÍA TES B & 877 & 41.872 & 236.104 & 543.241 & 1.291.394 & 1.776 .200 & 2.564 .370 & 3.539 .797 \\
\hline TOTAL & 133.138 & 280.273 & 385.918 & 645.756 & 1.514 .855 & 1.956 .985 & 2.797 .740 & 3.731 .335 \\
\hline PIB & 39.730 .752 & 52.271 .688 & 67.532 .862 & 84.439 .109 & 100.711 .384 & 121.707 .501 & 140.483 .322 & 151.565 .005 \\
\hline PARTICIPACIÓN DE INTERESES TES & $0,7 \%$ & $14,9 \%$ & $61,2 \%$ & $84,1 \%$ & $85,2 \%$ & $90,8 \%$ & $91,7 \%$ & $94,9 \%$ \\
\hline INTERESES TIITULOS TES B SOBRE PIB & $0,0 \%$ & $0,1 \%$ & $0,3 \%$ & $0,6 \%$ & $1,3 \%$ & $1,5 \%$ & $1,8 \%$ & $2,3 \%$ \\
\hline
\end{tabular}

Elaboración propia. Fuente: Contraloría General de la República.

TABLA 5. INTERESES DE LA DEUDA INTERNA DEL GOBIERNO NACIONAL CENTRAL POR PRESTAMISTA 2000-2006.

\begin{tabular}{|c|c|c|c|c|c|c|c|}
\hline FUENTE & 2000 & 2001 & 2002 & 2003 & 2004 & 2005 & 2006 \\
\hline Bonos nal. Deuda interna Ley 21/63 & 1.163 & 1.111 & 593 & 547 & 46 & - & - \\
\hline Títulos de ahorro nacional TAN & - & - & - & - & - & - & - \\
\hline Títulos de Tesorería TES B & 3.884 .895 & 3.711 .710 & 3.668 .103 & 4.664 .513 & 5.697 .427 & 7.149 .428 & 8.678 .546 \\
\hline Títulos de Tesorería TES A & 44.166 & 36.631 & 27.589 & - & 20.054 & - & - \\
\hline Títulos de Tesorería TES B - Dólares & 153.972 & 208.772 & 220.198 & 178.353 & 110.517 & 62.798 & 62.230 \\
\hline Bonso para la seguridad & 32.932 & 12.847 & 20.112 & 1.595 & 515 & 303 & 185 \\
\hline B V C universidades & 12.293 & 12.036 & 14.601 & 11.716 & 5.340 & 3.148 & 3.493 \\
\hline Bonos de solidaridad para la paz & 19.770 & 51.067 & 81.252 & 98.689 & 84.740 & 70.124 & 67.628 \\
\hline Títulos de Tesorería TES B - UVR & 191.955 & 421.619 & 565.121 & 849.503 & 1.038 .739 & 1.145 .442 & 1.128 .305 \\
\hline Títulos de Reducción de Deuda TRD & - & - & - & - & - & - & - \\
\hline Títulos de tesorería TES Ley 546 & 102.566 & 138.009 & 155.959 & 114.864 & 117.209 & 100.550 & 84.014 \\
\hline Títulos de tesorería TES - Corto plazo & - & - & - & - & 50.654 & 52.535 & \\
\hline TITULOS DE TESORERÍA TES B & 4.333 .387 & 4.480 .110 & 4.609.382 & 5.807 .232 & 7.014 .546 & 8.510 .754 & 9.953 .095 \\
\hline TOTAL & 4.652 .196 & 4.896 .902 & 4.994 .889 & 6.078 .805 & 7.249 .243 & 8.724 .299 & 10.112 .158 \\
\hline PIB & 174.896 .258 & 188.558.786 & 203.451.414 & 228.516 .603 & 257.746.373 & 285.312.864 & 320.727 .847 \\
\hline PARTICIPACIÓN DE INTERESES TES & $93,1 \%$ & $91,5 \%$ & $92,3 \%$ & $95,5 \%$ & $96,8 \%$ & $97,6 \%$ & $98,4 \%$ \\
\hline INTERESES TÍTULOS TES B SOBRE PIB & $2,5 \%$ & $2,4 \%$ & $2,3 \%$ & $2,5 \%$ & $2,7 \%$ & $3,0 \%$ & $3,1 \%$ \\
\hline
\end{tabular}

Fuente: Elaboración propia con base en Contraloría General de la República.

Según los resultados de la tabla anterior, es sorprendente la magnitud en la cual la carga de intereses a lo largo del periodo analizado ha superado a la del déficit primario, que en promedio ha sido de 2,6 veces y llegando a un niveles récord de 10,5 y 12 veces en 2004 y 2005, respectivamente. Esto nos lleva a inferir que si el problema de fondo no se encuentra en el excesivo nivel de gasto público sino en la gran cantidad de recursos destinados al pago de intereses, de nada han servido ni servirán las medidas de control del endeudamiento que se han dirigido al recorte del gasto -en su ritmo de crecimiento- cuando es evidente que son los intereses los que por "debajo de cuerda" están consumiéndose recursos que por mandato constitucional deben ir dirigidos al gasto social. 


\section{Solvencia financiera del Estado colombiano}

Evaluemos según la restricción presupuestal del Estado las consecuencias de esta carga de intereses. Dada la restricción presupuestal del Gobierno:

$$
b_{t+1}-b_{t}=g_{t+1}-\Pi_{t+1}+r_{t} b_{t}-\frac{H_{t+1}-H_{t}}{P_{t+1}}=d_{t+1}+r_{t} b_{t}
$$

Donde $d_{t}$ es el déficit primario en términos reales; $g_{t} y \Pi_{t}$ son respectivamente el gasto real del gobierno excluyendo los intereses de la deuda y la tributación real; $\mathrm{H}_{\mathrm{t}}$ es la base monetaria y el incremento real de su valor es el señoreaje.

Bajo el supuesto de que el gobierno eventualmente pagará la totalidad de sus deudas se definen los límites de sus déficits futuros. Según el enfoque neoclásico de la restricción presupuestal del gobierno, si la deuda está respaldada por superávits primarios futuros suficientes para cubrir el pago de intereses, se dice que el gobierno está en condiciones de solvencia favorables.

Dada la restricción (1), asumiendo una tasa de interés real constante $r$,

$$
b_{t}=\frac{s_{t+1}+b_{t+1}}{1+r}
$$

Extendiendo el plazo del endeudamiento hacia $\rightarrow \infty$, aplicando sumatoria

$$
b_{t}=\sum_{i=1}^{N} \frac{s_{t+i}}{(1+r)^{i}}+\frac{b_{t+N}}{(1+r)^{N}}
$$

Al ser obligado el estado a pagar la totalidad de la deuda en el plazo N, el último término $\rightarrow 0$ cuando $\mathrm{N} \rightarrow \infty$.

$$
b_{t}=\sum_{i=1}^{\infty} \frac{s_{t+i}}{(1+r)^{i}}
$$

Aunque la solvencia del sector público sea una condición indispensable para el sano funcionamiento y desarrollo del mercado financiero interno, existen errores de fondo en la definición anterior de solvencia, los cuales han sido descritos por Hermann (8) en dos puntos críticos: 
1. Al identificar el superávit primario del gobierno con relación al PIB como un instrumento para controlar la relación Saldo de la Deuda/ PIB, a través del control del Saldo de la deuda sin tener en cuenta también el efecto de un superávit primario en el PIB y sin tener en cuenta la influencia de la política de tasas de interés en el saldo total de la deuda.

2. Identificar la relación Saldo de la deuda/PIB como un indicador de solvencia financiera es demasiado limitado, pues no es el Stock de la deuda lo que define la capacidad financiera sino los flujos de ingresos y gastos - que no necesariamente acompañan a la relación saldo de la deuda/PIB- los que determinan esta condición.

Si definimos la restricción presupuestal del gobierno como:

$$
G_{t}=T_{t}+E B_{t} \quad[1]
$$

Donde $\mathrm{T}=$ Ingresos Tributarios, la cual se define como $T_{t}=t * Y_{t}$ donde $t$ es la tasa tributaria media de la economía y EB es la emisión de bonos nuevos realizada durante el periodo considerado.

El gasto total del gobierno $\mathrm{G}$ se define como:

$$
G=G P+G F \quad[2]
$$

Donde GP corresponde a los gastos primarios o no financieros y GF los pagos financieros del gobierno. Este último gasto a su vez se compone de:

$$
G F=A+I \quad[3]
$$

Donde A representa las amortizaciones sobre los títulos de deuda pública, igual a $A=a^{*} B$ e I representa el pago de intereses sobre los títulos, $I=i^{*} B$. De (2) y (3)

$$
\begin{array}{r}
G F=(a+i)^{*} B \\
E B=E B_{m}+E B_{B R}
\end{array}
$$

Donde $E B_{m}$ son los bonos emitidos adquiridos por el mercado y $E B_{B R}$ son los bonos emitidos adquiridos por el Banco de la República, igual a la variación de la base monetaria $d H$. 
De las definiciones anteriores se tiene que:

$$
\begin{gathered}
\mathrm{GP}+\mathrm{A}+\mathrm{I}=\mathrm{T}+\mathrm{EB}+\mathrm{dH} \\
(\mathrm{GP}-\mathrm{T})+\mathrm{I}=\left(E B_{m}-\mathrm{A}\right)+\mathrm{dH}
\end{gathered}
$$

$(\mathrm{GP}-\mathrm{T})+\mathrm{I}$ es el déficit nominal del gobierno, DN

$(\mathrm{GP}-\mathrm{T})$ es el déficit primario $=-\mathrm{SP}$

$\left(E B_{m}-A\right)=d B=$ Variación líquida en el stock de títulos de deuda. Entonces:

[6] $\mathrm{DN}=\mathrm{I}-\mathrm{SP}=\mathrm{dB}+\mathrm{dH}=\mathrm{dD}=$ variación líquida en la deuda total del gobierno.

Estabilizar la relación deuda/PIB en un nivel constante $\mathrm{k}=D_{0} / Y_{0}$ requiere cumplir que $d D / D_{0}=d Y / Y_{0}$.

De acuerdo con las condiciones anteriores:

$$
\begin{gathered}
\frac{d D}{D_{0}}=\frac{d D N}{D_{0}}=\frac{(I-S P)}{k * Y_{0}}=\frac{1}{k}(i *-s) \\
\text { Donde } \mathrm{i}^{*}=\frac{\mathrm{I}}{\mathrm{Y}_{0}} \text { y } \mathrm{s}=\frac{\mathrm{SP}}{\mathrm{Y}_{0}}
\end{gathered}
$$

Ahora, si expresamos $g=d Y / Y_{0}$ como la tasa de crecimiento nominal del PIB, la condición de estabilidad de $\mathrm{k}$ se cumple cuando:

$$
\begin{array}{r}
\quad \frac{1}{k}(i *-s)=\mathrm{g} \\
k=\frac{(i *-s)}{g}
\end{array}
$$

De acuerdo con el enfoque convencional, se tiene que $\mathrm{k}=$ constante que define el objetivo principal de gestión de la deuda pública, $\mathrm{i}^{*}$ e $\mathrm{g}$ son variables exógenas, s es la variable de ajuste que define el objetivo intermedio de la política. 
Para mantener un $\mathrm{k}$ constante, $\mathrm{s}$ debe ser elevado para compensar proporcionalmente cualquier aumento en i o reducción de g. Siendo i= $\mathrm{r}^{*}(\mathrm{~B} / \mathrm{Y})$, aumentos en i pueden ocurrir en función de aumentos en r o en $\mathrm{B}, \mathrm{o}$ de reducción en $Y$. Siendo B la deuda que ya está en el mercado, su magnitud refleja decisiones pasadas, relativas a las políticas fiscal y monetaria. La política fiscal determina el déficit nominal (DN), a ser financiado por $\mathrm{dB}$ o $\mathrm{dH}$. La política monetaria determina la distribución de $\mathrm{DN}$ entre $\mathrm{dB}$ y $\mathrm{dH}$, y a través de ésta, determina el costo $r$ (tasa de interés de los bonos), que será mayor cuanto mayor sea la parte $\mathrm{dB}$, es decir, entre más restrictiva sea la política monetaria, lo que hace un B mayor en el futuro próximo.

Así, en la fase de ajuste fiscal, en la que DN aun toma valores positivos y debe ser financiado en el mercado monetario, la magnitud necesaria de $\mathrm{s}$ para estabilizar la relación $k$ depende de la forma como viene siendo dirigida la política monetaria: s será mayor entre más restrictiva sea ésta política. En cuanto a $\mathrm{Y}$ y g, la tasa requerida s será mayor cuánto más recesivo sea el ambiente económico. Es decir, el modelo requiere una actuación procíclica de la política fiscal, lo que profundiza las tendencias recesivas o expansivas de la economía. Ésta es la antítesis del papel estabilizador que debe tener el gobierno en la economía, su eficacia puede ser nula en relación al objetivo que persigue, especialmente en ambientes económicos recesivos (8).

La siguiente tabla evalúa los siguientes parámetros en el caso de la economía colombiana:

TABLA 6. PARÁMETROS DE POLÍTICA FISCAL, POLÍTICA MONETARIA Y CRECIMIENTO ECONÓMICO. 1990-2010

\begin{tabular}{|c|c|c|c|c|c|c|c|c|c|}
\hline \multirow{2}{*}{ AÑO } & \multirow{2}{*}{$i^{*}$} & $\mathrm{~s}$ & g & $\begin{array}{c}\mathbf{k} \\
\text { estimado* }\end{array}$ & $\mathrm{k}$ real & $\begin{array}{c}\mathbf{k} \\
\text { OBJETIVO }\end{array}$ & $\begin{array}{c}\text { S } \\
\text { DESEADO }\end{array}$ & s objetivo & $\begin{array}{c}\text { G } \\
\text { DESEADO }\end{array}$ \\
\hline & & $\%$ & $\%$ & $\%$ & & $30 \%$ & $k=30$ & $\mathrm{~s}=1,3 \%$ & $\mathrm{~s}=1,3 \%$ \\
\hline 1990 & $1,09 \%$ & $0,34 \%$ & $35,83 \%$ & $2,09 \%$ & $14,7611 \%$ & 0,30 & $11,840 \%$ & 0,013 & $-1,41 \%$ \\
\hline 1991 & $1,17 \%$ & $0,95 \%$ & $29,55 \%$ & $0,74 \%$ & $14,0291 \%$ & 0,30 & $10,037 \%$ & 0,013 & $-0,91 \%$ \\
\hline 1992 & $1,03 \%$ & $-0,61 \%$ & $27,63 \%$ & $5,92 \%$ & $14,9882 \%$ & 0,30 & $9,313 \%$ & 0,013 & $-1,83 \%$ \\
\hline 1993 & $1,11 \%$ & $0,39 \%$ & $31,56 \%$ & $2,28 \%$ & $14,5463 \%$ & 0,30 & $10,584 \%$ & 0,013 & $-1,28 \%$ \\
\hline 1994 & $1,16 \%$ & $-0,22 \%$ & $29,20 \%$ & $4,70 \%$ & $12,6584 \%$ & 0,30 & $9,914 \%$ & 0,013 & $-1,14 \%$ \\
\hline 1995 & $1,23 \%$ & $-0,98 \%$ & $25,03 \%$ & $8,81 \%$ & $13,8936 \%$ & 0,30 & $8,737 \%$ & 0,013 & $-0,53 \%$ \\
\hline 1996 & $1,87 \%$ & $-1,75 \%$ & $19,27 \%$ & $18,75 \%$ & $14,4277 \%$ & 0,30 & $7,647 \%$ & 0,013 & $3,92 \%$ \\
\hline 1997 & $2,04 \%$ & $-1,70 \%$ & $20,85 \%$ & $17,93 \%$ & $17,7611 \%$ & 0,30 & $8,296 \%$ & 0,013 & $4,17 \%$ \\
\hline 1998 & $2,91 \%$ & $-2,08 \%$ & $15,43 \%$ & $32,33 \%$ & $22,1091 \%$ & 0,30 & $7,539 \%$ & 0,013 & $7,29 \%$ \\
\hline 1999 & $3,32 \%$ & $-2,59 \%$ & $7,89 \%$ & $74,81 \%$ & $29,5198 \%$ & 0,30 & $5,682 \%$ & 0,013 & $6,83 \%$ \\
\hline 2000 & $4,06 \%$ & $-1,85 \%$ & $15,39 \%$ & $38,42 \%$ & $36,9037 \%$ & 0,30 & $8,678 \%$ & 0,013 & $7,48 \%$ \\
\hline 2001 & $4,42 \%$ & $-1,50 \%$ & $7,81 \%$ & $75,82 \%$ & $44,1583 \%$ & 0,30 & $6,767 \%$ & 0,013 & $7,07 \%$ \\
\hline 2002 & $4,30 \%$ & $-1,17 \%$ & $7,90 \%$ & $69,30 \%$ & $50,3215 \%$ & 0,30 & $6,671 \%$ & 0,013 & $5,96 \%$ \\
\hline 2003 & $4,51 \%$ & $-0,36 \%$ & $12,32 \%$ & $39,53 \%$ & $50,7244 \%$ & 0,30 & $8,207 \%$ & 0,013 & $6,33 \%$ \\
\hline 2004 & $4,20 \%$ & $-0,25 \%$ & $12,79 \%$ & $34,83 \%$ & $46,4326 \%$ & 0,30 & $8,041 \%$ & 0,013 & $6,25 \%$ \\
\hline 2005 & $3,63 \%$ & $-1,37 \%$ & $10,70 \%$ & $46,72 \%$ & $46,5736 \%$ & 0,30 & $6,838 \%$ & 0,013 & $5,00 \%$ \\
\hline 2006 & $4,26 \%$ & $0,59 \%$ & $12,41 \%$ & $29,52 \%$ & $44,8954 \%$ & 0,30 & $7,982 \%$ & 0,013 & $6,59 \%$ \\
\hline 2007 & $4,44 \%$ & $0,97 \%$ & $7,50 \%$ & $46,15 \%$ & $41,1829 \%$ & 0,30 & $6,686 \%$ & 0,013 & $7,61 \%$ \\
\hline 2008 & $3,99 \%$ & $1,61 \%$ & $2,80 \%$ & $85,28 \%$ & $45,0463 \%$ & 0,30 & $4,833 \%$ & 0,013 & $5,98 \%$ \\
\hline 2009 & $4,14 \%$ & $-1,18 \%$ & $0,40 \%$ & $1328,47 \%$ & $49,6507 \%$ & 0,30 & $4,256 \%$ & 0,013 & $5,71 \%$ \\
\hline 2010 & $3,00 \%$ & $0,92 \%$ & $4,30 \%$ & $48,37 \%$ & $37,5200 \%$ & 0,30 & $1,710 \%$ & 0,013 & $4,53 \%$ \\
\hline
\end{tabular}

Fuente: Elaboración Propia con base en Cifras del Banco de la República. 
Las primeras tres columnas representan en su orden, la tasa $\mathrm{i}^{*}$ de intereses de la deuda sobre PIB, superávit primario como porcentaje del PIB y la tasa de crecimiento económico nominal registrada entre 1991 y 2010. En la columna 4 se obtiene el valor de $k$ que se habría dado bajo el supuesto que se cumple la condición de solvencia en el sentido neoclásico, de acuerdo a los valores de las columnas 1 a 3 . La columna 5 registra el valor efectivo. Con excepción del periodo entre 1991 y 1995 en que ligeros superávits primarios acompañados de bajos porcentajes de intereses y altas tasas de crecimiento nominal, la mayor parte de periodos reflejan que mientras el parámetro $i^{*}$ presenta un constante aumento la divergencia entre el nivel estable y el efectivo no es lo suficientemente amplia dadas las tasas de crecimiento económico, lo que indica cierta presión hacia el ajuste vía búsqueda del superávit primario.

Las columnas 6 y 7 prueban el nivel "deseable" de deuda/PIB del 30\% que ha sido pregonado bajo los lineamientos del FMI. La columna 7 indica la tasa de superávits primarios que acompañarían, dados los intereses sobre la deuda y el crecimiento económico a un equilibrio de la relación $\mathrm{k}$ del 30\%. Evidentemente en una economía en desarrollo tales niveles de superávit primario, siempre superiores al $4 \%$ son simplemente inalcanzables.

Las columnas 7 y 8 finalmente prueban un nivel de superávit primario sobre el PIB de 1,3\% según se ha consagrado recientemente en la agenda económica del gobierno. En este caso se estiman las tasas de crecimiento económico que se habrían obtenido dada esta ambiciosa meta, menores en la mayoría de caso a las que efectivamente se registraron.

Esta imposibilidad es analizada a nivel teórico en la ecuación anterior por Herman. Recordando que s depende de los recaudos tributarios y que los recaudos tributarios a su vez son función del ingreso, ya que $T=t^{*} Y$, en las fases recesivas la única manera de elevar los recaudos tributarios es elevando $t$ y que el ingreso $Y$ responde negativamente a aumentos en $s$, la medida puede tornarse inocua para reducir $\mathrm{D} / \mathrm{Y}$, ya que la reducción inicial en $\mathrm{D}$ tiende a ser acompañada rápidamente de una reducción en $Y$ $\mathrm{y}$ por tanto en $\mathrm{s}$

$$
s=\frac{S P}{Y}=\frac{T-G P}{Y}=t-\frac{G P}{Y}
$$


El problema reside en que en [7], Y no es dependiente de t y GP, tanto aumentos en $t$ como reducciones en GP implican reducción en $\mathrm{Y}$, eliminando el efecto inicial sobre s. Lo mismo ocurre en relación con $\mathrm{k}$, en la expresión [6], g no es independiente de s, el aumento inicial en s puede implicar disminución en g, anulando el esfuerzo inicial de reducción en k. Además de lo anterior, si la política no estuviera coordinada con un esfuerzo de ajuste fiscal, esta puede tornarse una lucha infructuosa. Como $\mathrm{i}=\mathrm{r}^{\star}(\mathrm{B} / \mathrm{Y})$, el aumento en $\mathrm{s}$ será inocuo.

El análisis sugiere que el camino virtuoso para el control y/o reducción de la relación k, no es el aumento ex-ante del superávit primario del gobierno, sino un aumento ex-post promovido por el crecimiento económico, lo cual es evidente en el año 2010, donde el crecimiento económico del 4,3\% "borró" una importante parte de la deuda. Para conseguir estos objetivos fue indispensable la política hacia la baja en las tasas de interés.

Por otra parte, en economías con sistemas de crédito bien organizados y desarrollados, el equilibrio financiero de un deudor no se define por su capacidad de liquidar completamente sus deudas, sino de honrar sistemáticamente los compromisos financieros adquiridos dentro de los plazos previstos (8).

De acuerdo con lo anterior, apenas dos condicionantes de la solvencia del sector público dependen de la gestión de la política fiscal: el término SP. Todos los demás son determinados por la política monetaria y por la forma de administración de la deuda pública. Esto demuestra que la coordinación entre la política monetaria y la política fiscal es una condición necesaria para la buena administración de la deuda pública.

Para describir las causas de este incremento vertiginoso en el componente $\mathrm{i}^{*}$ de la restricción presupuestal alegaremos tres factores dos de los cuales fueron descritos brevemente por Cabrera y González (9)² añadiendo un tercer factor. Estos se resumen como: i) La prohibición a acceder a los recursos de emisión y crédito del Banco de la República con el objetivo fundamental de preservar la estabilidad de precios, ii) El manejo procíclico de la política monetaria que indujo durante la mayor parte del periodo a

\footnotetext{
${ }^{2}$ El trabajo de Cabrera y González (9) explica tres razones para el crecimiento explosivo de la deuda pública: i) La decisión de no acudir al crédito del Banco de la República ii) La política de altas tasas de interés y iii) La forma como se ha redistribuido el impuesto por inflación. Debido a que este último factor se refiere más que todo al manejo de los encajes bancarios como instrumento de política monetaria ha sido añadido al numeral ii), y se ha decidido abordar de manera apartada la estrategia de manejo de los TES, al ser el factor considerado de mayor importancia.
} 
altísimas tasas de interés y iii) Las estrategias de colocación de Títulos de Tesorería y el manejo de las inversiones en los mercados financieros. Veamos cómo ha influido cada uno de ellos:

\section{i) La independencia del Banco Central y la prohibición a} acceder a los recursos de emisión.

Este componente institucional para los ingentes pagos de intereses está consignado en el artículo 373 de la Constitución Nacional, el cual reza que:

“(...) el Banco no podrá establecer cupos de crédito, ni otorgar garantías a favor de particulares, salvo cuando se trate de intermediación de crédito externo para su colocación por medio de los establecimientos de crédito, o de apoyos transitorios de liquidez para los mismos. Las operaciones de financiamiento a favor del Estado requerirán la aprobación unánime de la Junta Directiva, a menos que se trate de operaciones de mercado abierto. El legislador, en ningún caso, podrá ordenar cupos de crédito a favor del Estado o de los particulares".

Esta decisión implicó que en tan solo 5 años el Banco de la República pasara a ser el prestamista número 1 del Estado, con un 49,2\% de sus acreencias en 1990 a ser tener tan solo el 9,6\% en 1995 y haya desaparecido por completo en 1998. En este mismo periodo (1990-1995) los Títulos de Tesorería TES pasaron de representar el 0\% de la deuda interna del gobierno nacional al 71,2\% en 1995 y el pago de intereses de la deuda pasó de representar el 1\% del PIB en 1990 al 4,14\% en 2009.

\begin{tabular}{|}
$\begin{array}{c}\text { TABLA 7. INTERESES DE LA DEUDA DEL GOBIERNO } \\
\text { CENTRAL (\%PIB) 1985-1990 }\end{array}$ \\
Intereses (\%PIB) \\
\hline 1.985 & $0,9 \%$ \\
\hline 1.986 & $0,9 \%$ \\
\hline 1.987 & $1,1 \%$ \\
\hline 1.988 & $1,2 \%$ \\
\hline 1.989 & $1,2 \%$ \\
\hline 1.990 & $1,1 \%$ \\
\hline
\end{tabular}

Fuente: Banco de la República

La mayor parte de los estudios que tratan la independencia del Banco Central y la inflación se basa en una metodología desarrollada por Bade y 
Parkin (1982) a través de un enfoque consistente en hallar la relación entre la medida de independencia del Banco central elegida y el desempeño inflacionario, mediante diagramas de dispersión o con modelos formales de regresión.

Cargill (1996) demuestra que el desempeño inflacionario del Banco del Japón y de la Reserva Federal contradice la existencia de esa asociación y concluye que en las discusiones sobre la reestructuración de los bancos centrales para estabilizar los precios no se debería dar tanta importancia a dicha asociación estadística, pues los resultados no son estadísticamente robustos. Mediante la estimación de regresiones simples, Cargill ilustra la sensibilidad de la asociación estadística entre cambios razonables en la especificación y los periodos y encontró que la correlación negativa entre desempeño inflacionario e indicadores de independencia del Banco Central se debilita o desaparece al cambiar la especificación del modelo y los países incluidos en la regresión.

La relación entre la independencia del Banco de la República con los altos intereses de la deuda pública emanan del hecho de que al proclamarse la imposibilidad de acudir a la emisión directa hacia la financiación de los déficits públicos: 1) Se obliga al gobierno a competir por recursos a tasas establecidas por compradores oligopolistas violando la potestad que tiene el estado sobre la creación y destrucción de moneda, obstruyendo el canal natural de la expansión monetaria a la creación de valor 2) la utilización de la tasa de interés de los TES-B como tasa de intervención en el mercado monetario fomenta las prácticas especulativas en los mercados financieros, que optarán por desviar el ahorro de la economía desde la cartera crediticia a las inversiones en TES siempre que la tasa de crédito interbancario sea menor a la tasa que rentan los TES. Es decir, se obliga a los títulos a preservar tasas altas aun cuando en rigor la deuda pública deba ser de menor costo dado que se cubre el riesgo soberano.

\section{ii) El manejo procíclico de la política monetaria}

Una de las dificultades más grandes por las cuales atravesó la economía, en especial en la década de los 1990s, fue la inexistencia de una coordinación adecuada entre las políticas del Banco de la República y las decisiones de Tesorería. En especial, en 1995 se enfrentan en un mismo escenario una política fiscal expansiva dirigida por la orden constitucional de ampliar la acción del Estado en materia social, una política monetaria contractiva que se tradujo en elevadísimas tasas de interés, una expansión 
de la demanda de crédito privado y un alza sostenida de la revaluación debido a la masiva entrada de capitales. Todos estos factores combinados produjeron una reducción del ritmo de la actividad económica al tiempo que la política del Banco de la República, en especial la política monetaria tomaba medidas que redundaban siempre en mayores tasas de interés y mayor entrada de capitales, agravando la situación.

A raíz de las reformas estructurales fundamentadas en el consenso de Washington, el gobierno recaudó recursos provenientes principalmente de la privatización de bancos públicos, empresas generadoras de energía eléctrica y concesión del espectro electromagnético que contó con una gran participación compradores extranjeros, por lo que las divisas que entraron al país, en conjunto con las provenientes de las crecientes exportaciones de petróleo, así como la amnistía que en 1992 la reforma tributaria ofreció para repatriar capitales, produjeron una sobreoferta que ocasionó una fuerte revaluación del peso. La bonanza cambiaria que vivió el país hasta 1996 fue un factor bastante favorable en materia de pagos de deuda, pues permitió realizar un considerable volumen de prepagos de deuda externa que explican la reducción del saldo de la deuda externa como porcentaje del PIB del 12,4\% al 7,2\% entre 1990 y 1996.

En cuanto al manejo de la política monetaria, entre los años 1991 y 1994 la principal característica fue la gran expansión monetaria, la cual inició cuando el emisor decidió implementar el encaje marginal para frenar el crecimiento del crédito en 1991, por lo que los intermediarios de la banca invirtieron el dinero de sus captaciones en OMAS del Banco de la República. El ingreso masivo de dólares que se dio después obligó al Banco de la República a comprar divisas emitiendo efectivo y ampliando el crecimiento de los medios de pago a tasas anuales de $42 \%$ en 1992 y 37\% en 1993. Para bajar ese crecimiento el banco aplicó una política de contracción monetaria con emisión masiva de Títulos de Participación a partir de 1994, llevando los medios de pago de ese año a una evolución de $28,6 \%$ y de 19,7\% en 1995. Según cifras del Ministerio de Hacienda, en 1995 el gobierno colocó \$2,4 billones de pesos en TES que contrastaron con el saldo de las OMAS al cierre de ese año por \$216.000 millones (10).

En 1994 y 1995 el presupuesto nacional contemplaba partidas presupuestales financiadas con TES por $\$ 4,8$ billones, lo cual empezó a generar expectativas sobre los efectos de este endeudamiento en las tasas de interés. La utilización de TES en 1995 fue fijada como el 43\% de la variación anual de los activos financieros de la economía. Según el diario 
el Tiempo (1993, 12 de Agosto) "Si el monto de los TES se compara con el valor de los gastos que aparecen en el Presupuesto de la Nación, se tiene que en 1995 representará el 15\%, cifra que está muy por encima del uno por ciento del periodo 1987-91".

GRÁFICO 6. BASE MONETARIA (CRECIMIENTO PORCENTUAL), DTF, INFLACIÓN Y CRECIMIENTO NOMINAL DEL PIB. 1990-2010

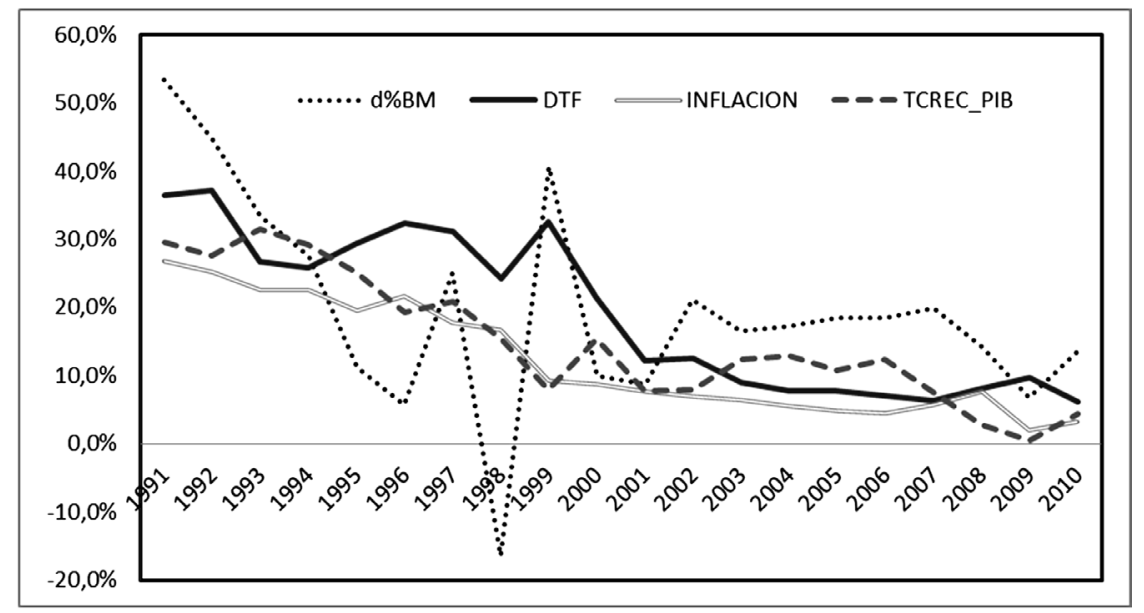

Fuente: Elaboración propia con base en Cifras del Banco de la República.

Las suspicacias sobre la naturaleza de los TES y su uso como instrumento de financiación se hacen evidentes en la prensa nacional desde 1994. El 7 noviembre de 1994 el diario el tiempo en un artículo denominado $\mathrm{La}$ cuadratura del círculo (11) señala que:

“En el pasado, el gobierno había hecho un uso modesto de los recursos del endeudamiento interno en los mercados financieros. Sin embargo, debió recurrir a esta fuente de financiamiento ante la imposibilidad de apelar a los recursos de la emisión monetaria, como resultado de las reformas constitucionales y legales que regulan el Banco de la República y ante la inconveniencia de recurrir al endeudamiento externo en las actuales circunstancias, debido al exceso de liquidez en moneda extranjera por la que atraviesa la economía colombiana, lo cual está generando presiones revaluacionistas".

Este mismo artículo señala dos factores que se avizoran como causas para un mayor endeudamiento: la entrada masiva de divisas, que obligaría al Banco de la República a una intervención más activa para evitar que la expansión de los medios de pago impida el cumplimiento de las metas 
de inflación y la presencia del Gobierno compitiendo en el mercado por obtener liquidez, que lo obligaría a aumentar su rentabilidad para atraer los recursos del público, ambos actuando a través de un incremento en las tasas de interés.

Desde 1995 son más frecuentes las advertencias de los peligros por los que atraviesa la economía. La Junta Directiva del Banco de la República determinó restricciones a las tasas de interés de colocación de los Bancos y permitió el incremento de la tasa de crecimiento de los medios de pago del $17,6 \%$ al $24,5 \%$, redimiendo títulos de participación que estaban próximos a vencerse por más de $\$ 200.000$ millones (12).

Desde enero de 1996 se prevé una coyuntura de altas tasas de interés explicada por varios factores, entre los cuales se señala la competencia más alta del gobierno por captar recursos del ahorro interno a través de los Títulos TES, la certeza de que el Banco de la República mantendría una línea dura de control a los medios de pago, al crecimiento del crédito de consumo y la restricción al endeudamiento externo, la progresiva recuperación de la inversión interna privada y el aumento de los encajes sobre las captaciones a través de CDT y la contracción monetaria originada en el déficit cambiario (El tiempo, 1996 Enero 15).

La economía colombiana presentaba varios síntomas de que las cosas no iban muy bien. En este momento se inauguró una era de debates sobre quiénes eran los responsables de la coyuntura de altas tasas de interés, si el Banco de la República por su manejo del crédito o el Ministerio de Hacienda por el excesivo crecimiento del gasto. Por un lado el viceministro técnico de Hacienda, Leonardo Villar, sugería como necesario reducir en tres o cuatro puntos las tasas de interés teniendo en cuenta los fuertes indicios de desaceleración en la economía.

Mauricio Cabrera Galvis, en ese entonces presidente de la Fundación para la Educación Superior, sugirió eliminar los encajes en CDTs, aumentar el endeudamiento en dólares de los bancos y modificar la corrección monetaria, y señaló que gran parte de la responsabilidad en el alto nivel de tasas de intereses en ese momento lo tenía el Banco de la República por no suministrar a tiempo liquidez al mercado (El tiempo, 1996, 27 de Abril). Por otra parte, el codirector del Banco de la República, Hernando José Gómez, culpó al Gobierno por no frenar el gasto público. Cabrera contradijo lo anterior afirmando que el Gobierno no había forjado al alza la tasa de interés porque realmente no estaba compitiendo de una manera dramática por los recursos, mediante emisiones de TES. 
No obstante, al observar las cifras podemos cerciorarnos de que el menor ritmo de la actividad económica presentado a partir de 1995 estuvo muy ligado al menor crecimiento monetario implementado por el Banco de la República para controlar la expansión del gasto. Los agregados monetarios presentaban un crecimiento lento, menor a las metas de crecimiento aprobadas por la Junta Directiva del Banco de la República y al menor crecimiento del PIB nominal y la inflación.

GRÁFICO 7. CRECIMIENTO PORCENTUAL ANUAL M1 Y DTF

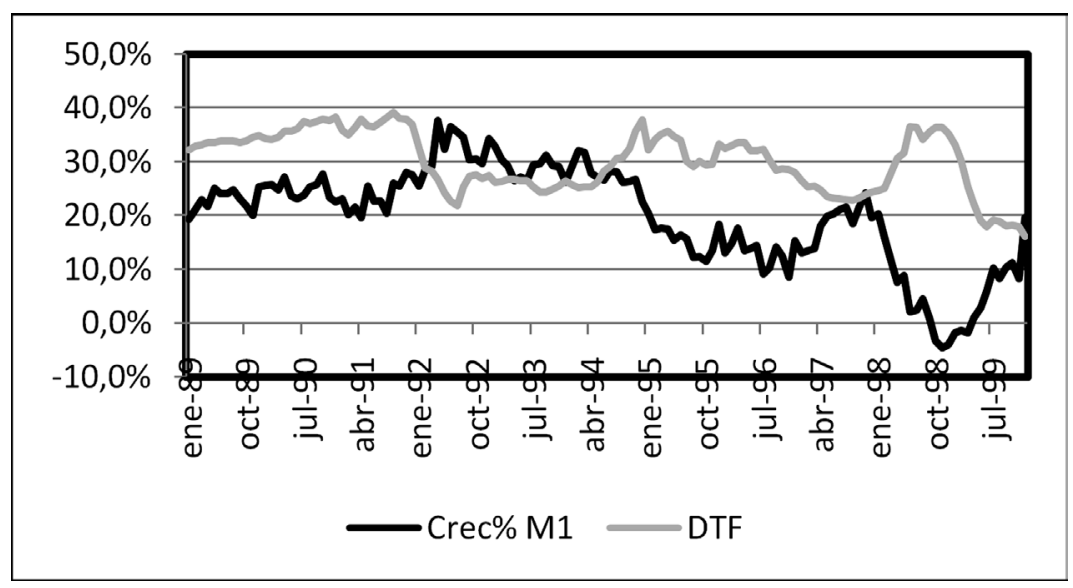

Fuente: Elaboración propiacon base en Cifras del Banco de la República.

Según datos de la Asociación Nacional de Entidades Financieras (ANIF), en agosto el M1 crecía al 10,3\% anual, el M2 al 16,3\% y el M3 al 16\%, mientras que la inflación se situó en el 21,05\% y el crecimiento nominal del PIB superaba el 22\%. La desaceleración también fue consecuencia de la crisis política, que aumentó el freno de la economía, afectando las expectativas de los agentes, que disminuyeron la inversión, aumentó el riesgo percibido en las tasas de interés y se aceleró la devaluación más de lo previsto. La crisis política generó una caída en las reservas internacionales, lo cual generó una caída en la cantidad de dinero en circulación y la situación de iliquidez que se vivió entre mediados de 1996 y primer trimestre de 1997 con la consecuente subida de los intereses (13).

Hasta este punto cabe realizar algunas conclusiones sobre los problemas del manejo de las políticas hasta este momento. En primer lugar los inconvenientes derivados del exceso de reservas internacionales eran de esperarse por la forma como se manejó el programa de privatizaciones del gobierno, y la política monetaria no hizo lo que tenía que hacer, puesto que el alza continua de interés que tomo como medida para evitar 
la inflación causada por la monetización de divisas solo logró agravar el problema.

Ante un escenario de inflación de este tipo el alza de intereses es una política simplemente inocua para el control de la inflación, y con resultados muy devastadores para la carga de intereses de la deuda. Aunque hubo un gran volumen de colocación de títulos que tenían como referencia las tasas de mercado, la mayor parte de las colocaciones fueron inversiones convenidas con el Instituto de Seguros Sociales y las tasas de interés solían ser más bajas que estas tasas, por lo que el gran culpable del encarecimiento del endeudamiento de la deuda en este periodo fue, sin duda, el mal manejo de la política monetaria.

El periodo que transcurre desde 1997 hasta el año 2002 está caracterizado por el aumento simultáneo de las fuentes internas y externas de financiamiento. El saldo total de la deuda crece en un $195 \%$ en este periodo, mientras en 1997 este registró el 17,8\% del PIB ya en el año 2000 este porcentaje es del 52,7\%. Mientras el aumento del endeudamiento externo fue del $128,2 \%$, desde el $8,5 \%$ al $25,4 \%$ del PIB para los años respectivos el endeudamiento interno creció en un $120 \%$, desde el $9,3 \%$ al 27,3\% con relación al PIB. Los principales determinantes fueron los factores de mercado, debido a que en este periodo se reflejó el impacto de remunerar a tasas de mercado toda la deuda interna.

Así mismo la devaluación, que acumuló más de 40 puntos reales en este periodo y la reducción del crecimiento económico por efecto de la crisis de finales de la década, incrementaron los niveles de deuda externa como proporción del PIB. Desde luego, también contribuyó con este mayor endeudamiento el déficit primario y, finalmente, la asunción de algunos pasivos por parte del Gobierno. Esta combinación de devaluación y reducción del crecimiento, aunada a la restricción al financiamiento externo presionó a la búsqueda de recursos internos.

En el periodo entre 2001 y 2006, finalizada la profunda recesión económica, se observó un relativo viraje en la política monetaria ahora concentrada más que en el objetivo de la reducción de la inflación, en la intervención en el mercado cambiario con el fin de controlar la revaluación. Por estos años el debate monetario fue menos intenso y caracterizado por poca controversia, fundada en la complacencia tanto a los interesados en una abundante liquidez como a los defensores acérrimos de la lucha antiinflacionaria. Las metas de inflación fueron de cierta forma poco ambiciosas y la liquidez se manejó con alguna laxitud, pues el exceso de liquidez que se presentó 
entre 2001 y 2006 no se reflejaría en un desbordamiento del nivel de precios debido a la competencia internacional con un dólar barato y por el exceso de capacidad instalada que había dejado la crisis. (Portafolio, Marzo 21 de 2007).

Pero realmente fue la excepcional coyuntura económica el factor más incidente para lograr el objetivo de baja inflación más que las acciones del Banco de la República. En primer lugar la etapa post-recesión dejó un ingente exceso de capacidad instalada de todos los factores y en todos los sectores. Segundo, la revaluación del peso propiciada por la debilidad del dólar a nivel internacional significó en la práctica tener un techo relativamente firme para los precios de todos los bienes y servicios transables. Tercero, el impacto del crecimiento de la base monetaria en la demanda agregada estuvo fuertemente amortiguado por el efecto del 4 por mil en la intermediación de los recursos monetarios y su rotación. E incluso en medio de estas condiciones el descenso de la inflación se dio en un proceso paulatino y modesto desde el 7\% al finalizar 2001 hasta el 5,25\% en febrero de 2007, aunque en 2006 llegó a bordear el 4\% (Portafolio, Marzo 21 de 2007).

TABLA 8. DETERMINANTES DE LA VARIACIÓN DEL SALDO DE LA DEUDA

DEL GNC 1991-2009

\begin{tabular}{|c|c|c|c|c|}
\hline AÑ & Ddeida/pib & DP/PIB & iD/PIB & $\begin{array}{c}\text { TRM(i*) } \\
\text { PIB) }\end{array}$ \\
\hline 1991 & $-0,007$ & $-0,010$ & 0,012 & $-0,009$ \\
\hline 1992 & 0,010 & 0,006 & 0,010 & $-0,007$ \\
\hline 1993 & $-0,004$ & $-0,004$ & 0,011 & $-0,012$ \\
\hline 1994 & $-0,019$ & 0,002 & 0,012 & $-0,033$ \\
\hline 1995 & 0,120 & 0,010 & 0,012 & $-0,010$ \\
\hline 1996 & 0,005 & 0,017 & 0,019 & $-0,031$ \\
\hline 1997 & 0,033 & 0,017 & 0,020 & $-0,004$ \\
\hline 1998 & 0,043 & 0,021 & 0,029 & $-0,006$ \\
\hline 1999 & 0,074 & 0,026 & 0,033 & 0,015 \\
\hline 2000 & 0,074 & 0,019 & 0,041 & 0,015 \\
\hline 2001 & 0,073 & 0,015 & 0,044 & 0,013 \\
\hline 2002 & 0,062 & 0,012 & 0,043 & 0,007 \\
\hline 2003 & 0,004 & 0,004 & 0,042 & $-0,045$ \\
\hline 2004 & $-0,043$ & 0,003 & 0,042 & $-0,087$ \\
\hline 2005 & 0,001 & 0,014 & 0,036 & $-0,049$ \\
\hline 2006 & $-0,017$ & $-0,006$ & 0,043 & $-0,053$ \\
\hline 2007 & $-0,037$ & $-0,010$ & 0,044 & $-0,072$ \\
\hline 2008 & 0,039 & $-0,016$ & 0,040 & 0,015 \\
\hline 2009 & 0,046 & 0,012 & 0,041 & $-0,007$ \\
\hline 2010 & $-0,121$ & 0,009 & 0,030 & $-0,160$ \\
\hline
\end{tabular}

Fuente: Elaboración propia con base en: Banco de la República. 
Por último, realizando un ejercicio sencillo propuesto por Cabrera y González (9), examinamos la influencia de la revaluación de la tasa de cambio en materia de reducción del saldo de las acreencias del GNC. La metodología es simple: primero se calcula el crecimiento anual absoluto de la deuda/PIB (miembro izquierdo de la identidad), y se compara con dos cifras flujo, déficit primario sobre PIB y pagos de intereses sobre PIB. Las diferencias entre unos y otros por simplicidad puede entenderse como las variaciones en la tasa de cambio.

En la década de los 1990s, en la mayoría de periodos la revaluación de la tasa de cambio propició un alivio en la carga de la deuda/PIB, en especial en el año 1996 en que la rigidez de la política monetaria desencadenó una fuerte entrada de capitales y la revaluación más alta de la década y con excepción de los años 1992 y 1999 que coinciden con periodos de devaluación de la tasa de cambio. Por otra parte vemos como la revaluación ha jugado un papel muy importante a partir de 2003, lo que en parte ha explicado la mejor posición de las acreencias del Estado desde el año 2000.

Utilizando razones simples entre las variables dela restricción presupuestal podemos determinar para cada año los parámetros que relacionan el grado de influencia absoluta entre la variación de la deuda y cada uno de sus componentes, a fin de establecer alguna medida de mayor o menor determinación de cada factor en los resultados totales.

La última columna de la tabla siguiente establece que para la totalidad del periodo comprendido los intereses de la deuda interna tienen en promedio el doble de "peso" sobre la variación total de la deuda que el déficit primario, mientras la revaluación nominal de la tasa de cambio tiene un peso casi tan alto en la disminución de la deuda como los intereses en su expansión. 
TABLA 9. PARÁMETROS DE RELACIÓN ENTRE VARIACIÓN DE LA DEUDA

PÚBLICA Y SUS COMPONENTES BÁSICOS

\begin{tabular}{|c|c|c|c|}
\hline $\mathbf{A N N O}$ & (DP/PIB)/(Ddeuda/PIB) & (iD/PIB)/(Ddeuda/PIB) & TMR(i* $\left.\mathbf{D}^{*} / \mathbf{P I B}\right) /($ Ddeuda/PIB) \\
\hline 1991 & 1,305 & $-1,602$ & 1,298 \\
\hline 1992 & 0,637 & 1,069 & $-0,707$ \\
\hline 1993 & 0,893 & $-2,521$ & 2,628 \\
\hline 1994 & $-0,115$ & $-0,612$ & 1,727 \\
\hline 1995 & 0,792 & 0,993 & $-0,786$ \\
\hline 1996 & 3,272 & 3,492 & $-5,764$ \\
\hline 1997 & 0,509 & 0,612 & $-0,121$ \\
\hline 1998 & 0,478 & 0,67 & $-0,147$ \\
\hline 1999 & 0,349 & 0,447 & 0,204 \\
\hline 2000 & 0,251 & 0,55 & 0,199 \\
\hline 2001 & 0,207 & 0,61 & 0,183 \\
\hline 2002 & 0,19 & 0,698 & 0,112 \\
\hline 2003 & 0,89 & 11,197 & $-11,088$ \\
\hline 2004 & $-0,059$ & $-0,979$ & 2,038 \\
\hline 2005 & 9,704 & 25,748 & $-34,452$ \\
\hline 2006 & 0,354 & $-2,538$ & 3,184 \\
\hline 2007 & 0,262 & $-1,195$ & 1,932 \\
\hline 2008 & $-0,416$ & 1,034 & 0,382 \\
\hline 2009 & 0,256 & 0,898 & $-0,154$ \\
\hline 2010 & $-0,074$ & $-0,247$ & 1,321 \\
\hline
\end{tabular}

Fuente: Elaboración propia

\section{iii) El manejo de la deuda interna a través de TES}

Entre 1991, cuando los TES aparecen como instrumento para la financiación del Estado y $1998^{3}$ la mayor parte de las colocaciones se realizaron en el segmento del mercado correspondiente a entidades públicas y las empresas financieras y comerciales del Estado. Los principales tenedores de TES eran el ISS y los fondos de pensiones. Desde 1998 se establece que el sistema de Creadores de Mercado, que inició con 11 instituciones oficialmente creadores y 8 aspirantes a creadores de mercado.

Se ha señalado que la falla de este sistema de intermediarios ciegos en el mercado ha sido gran determinante del repunte de las tasas de interés de los títulos, lo cual ha significado mayores beneficios para sus

\footnotetext{
${ }^{3}$ La información sobre las subastas de Títulos en el mercado primario se encuentra recopilada por el Departamento de Operaciones y desarrollo de mercados de la Subgerencia Monetaria y de Reservas del Banco de la República únicamente desde el año 1998. De los años anteriores se obtuvo información muy limitada en el documento "Titulos de Tesorería TES" del Grupo de Capitales Interno del Ministerio de Hacienda.
} 
poseedores y una mayor participación de los Títulos TES en el portafolio de inversiones de las instituciones financieras y privadas. El gráfico nos permite analizar lo anterior. Mientras antes de 1998 la mayor parte de los TES B se encontraban en manos del sector público, a partir de este año vemos como el sector financiero y privado adquieren, en el transcurso de pocos años la mayor parte de la participación en las tenencias totales de tales títulos.

La principal anotación que se ha hecho al respecto está relacionada con los plazos y las tasas a las cuales han sido captados estos títulos, que la mayoría de periodos superan la tasa de referencia del mercado -DTF. Entre 1998 y 1999 este factor se ha señalado como uno de los determinantes claves de la contracción del crédito, pues ante el ambiente de gran incertidumbre las entidades financieras suspenden la inversión en cartera para desplazarse a alternativas de mayor rentabilidad y mínimo riesgo.

GRÁFICO 8. TENENCIAS HISTÓRICAS DE TES B POR SECTOR

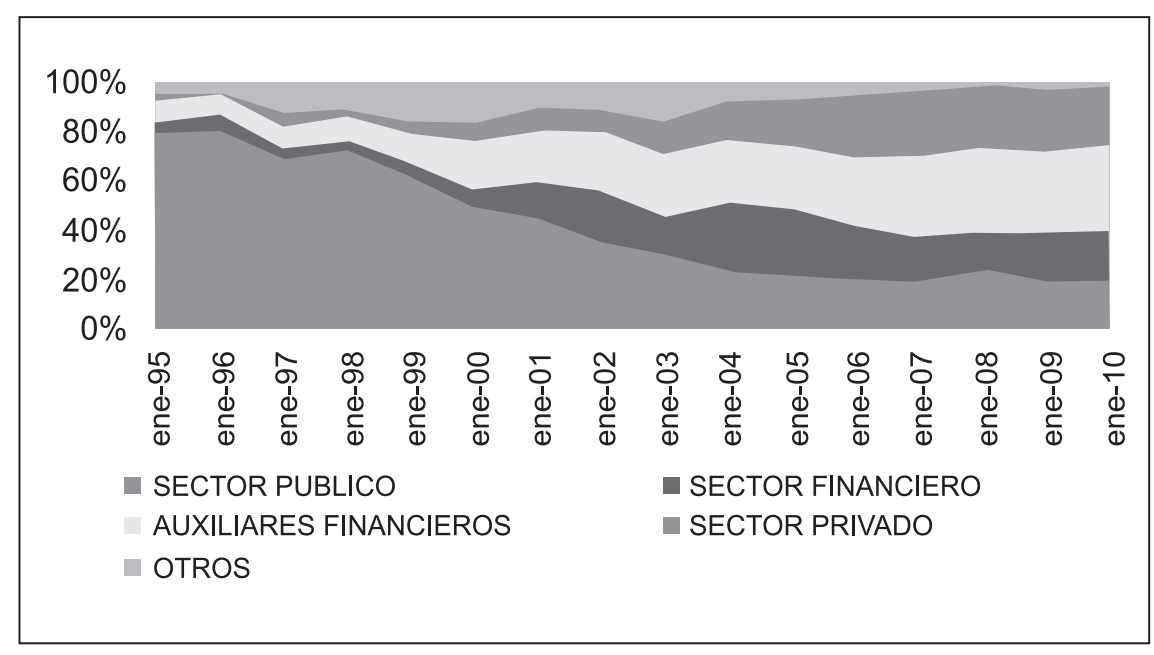

Fuente: Banco de la República. Boletines anuales del sistema de pagos.

Por ejemplo, informes de la Contraloría General de la República indican que la colocación de TES que se dio desde el segundo semestre de 1998 fue la más costosa y más errada de la época. Los factores que explicaron esto fueron, primero, la decisión de aumentar las colocaciones a largo plazo, de manera que los títulos a más de cinco años alcanzaron el $40 \%$ del saldo de circulación en diciembre de 1999 cuando dos años atrás apenas representaron el 13\% (9). 


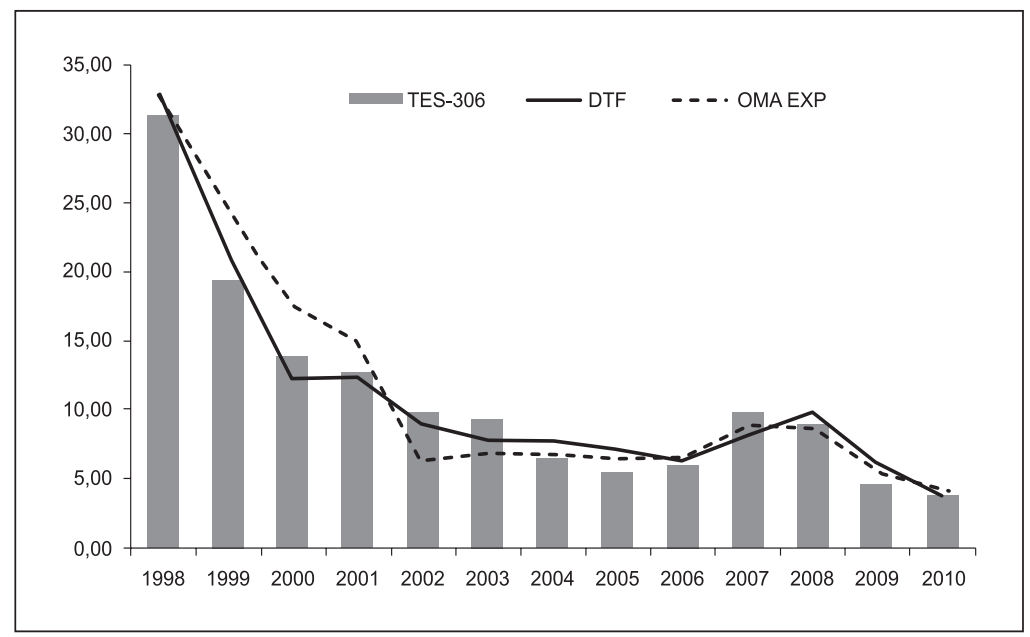

Fuente: Elaboración propia con base en Banco de la República.

Castiblanco (14) realizó una estimación del sobrecosto de los TES subastados entre 1998 y 2000 con base en la diferencia entre el costo de los intereses pagados por los títulos colocados a tasa fija y el que se hubiera pagado ante tres escenarios hipotéticos: 1) IPC $+10 \%$, 2) DTF y 3) Tasa de interés de mercado al vencimiento de cada uno de los años. El resultado de este ejercicio arrojó que los sobrecostos de las tasas fijas ante las primeras dos alternativas oscilaban entre los $\$ 183.000$ millones y los $\$ 278.000$ millones. Pero si la comparación se realiza entre el valor facial de la deuda total y su rendimiento, y las tasas de interés de mercado vigentes para cada uno de los años en referencia, el sobrecosto fiscal que se desprende alcanza los $\$ 2,2$ billones.

Los resultados de esta estimación nos permiten reflexionar sobre el potencial de lucro de las inversiones en TES, razón por la cual, los excedentes de liquidez del sistema financiero, de estar invertidos en TES en un $13,2 \%$ de su portafolio en 1998, pasaron a participar con $23,6 \%$ en el año 2000. Los fondos de pensiones privados, por otra parte, pasaron de tener el 1\% de sus activos invertidos en TES B en 1997 al 7,8\% en 1999 y al $11,1 \%$ en el año 2000 ((9); (14)).

De igual forma, en años recientes la tendencia hacia el sobrecosto implícito en las operaciones de canje ha sido señalada repetidas veces por la Contraloría General de la República en el contenido de sus informes anuales de deuda pública. Recordando la idea Keynesiana de que el gobierno tiene un trade-off entre elegir plazos cortos de 
endeudamiento que representen bajos costos financieros de la deuda y una alta presión fiscal por recursos en el corto plazo, versus, largos plazos de endeudamiento con altos costos financieros y baja presión fiscal en el corto plazo, es evidente que el gobierno nacional ha elegido la estrategia más costosa y a la vez más redituable para los tenedores de deuda.

En el informe de deuda pública versión 2009, la entidad pone de relieve el carácter procíclico de la valorización de los portafolios de TES, destacando que en momentos de incertidumbre como los vividos en el año 2009, cuando la crisis financiera y económica mundial y sus efectos sobre la producción y la demanda internas llevaron a una reducción de la inflación del 7,67\% al 2,0\% entre enero y diciembre produjeron una considerable reducción de las tasas de referencia por parte del Banco de la República desde el 9,5 al 3,5\%, lo cual provocó una valorización importante de los portafolios de TES del sector privado y financiero que explicó buena parte de los excelentes resultados presentados por las entidades del sector financiero, las cuales reportaron unas utilidades de $\$ 8,5$ billones ( $\$ 2,0$ billones más que lo registrado en 2008), al igual que los fondos administrados que obtuvieron una cifra record de utilidades de $\$ 28,1$ (\$23,9 billones más que en 2008) en un contexto económico nacional y mundial caracterizado por la crisis o bajo crecimiento.

El costo potencial de las operaciones de canje está en función de las tasas de interés en el periodo de vencimiento de los títulos intercambiados. Si el intercambio se realiza a tasas superiores a las efectivas en el futuro se produce un costo fiscal y si estas están en alza, la operación representa un ahorro. Por tanto, es importante tener en cuenta al evaluar la efectividad de estas operaciones si se están realizando a tasas que reflejen las expectativas futuras de tasas de interés, de manera que no se logre disminuir las presiones del financiamiento a corto plazo al coste de un endeudamiento más oneroso.

Por ejemplo, durante 2004 se realizaron canjes de TES por un monto de $\$ 2,1$ billones en 13 operaciones de intercambio, de las cuales 12 se efectuaron en forma directa con entidades públicas o sociedades fiduciarias que administran recursos públicos, por un monto de $\$ 760$ millardos. En las operaciones realizadas durante el año 2004, la tasa de rentabilidad de los títulos canjeados se situó entre el $4 \%$ y el $8 \%$, mientras que las de los títulos nuevos oscilaron entre el 10\% y el 14\%, lo que se convirtió en un atractivo para los tenedores de TES, pero en costos mayores para quien paga estos intereses (15). 
Hernández (15) realiza un estimativo de los costos de las operaciones de canje realizadas en 2004 consistente en calcular los intereses para los títulos que se intercambiaron por el plazo residual que aún les faltaba para su vencimiento, con el fin de compararlos con los intereses que arrojaban los nuevos TES entregados en el canje para ese mismo periodo de tiempo. El resultado de esta comparación arrojó una diferencia de intereses adicionales por $\$ 34.000$ millones que sobre los TES emitidos se debían cancelar, frente al que hubiese que pagar de no haber anticipado el vencimiento de TES intercambiados, lo que significó que mantener los nuevos títulos tantos días como los que le faltaban a los viejos para su maduración, implicaba un incremento del $27 \%$ en el pago de intereses. El cupón medio de la deuda canjeada fue del 10,5\% frente al 11,9\% de la deuda emitida, es decir, un 1,4\% superior, lo que implicaría un aumento en la carga de los intereses.

En 2005 se intercambiaron títulos TES a mayores tasas, primando la necesidad del aplazamiento de los pagos. Además, el Gobierno realizó canjes de papeles a los que sólo les restaba un día al vencimiento, es decir, sustituyó el roll over voluntario del acreedor por un canje obligatorio del deudor. Por lo tanto, los canjes internos realizados en el periodo 2002-2005, exceptuando 2003, fueron costosos en razón de que los intereses de los títulos nuevos superaron los intereses de los títulos retirados (CGR, 2005)

TABLA 10. COSTOS DE LOS CANJES DE DEUDA INTERNA. MILLONES DE PESOS

\begin{tabular}{|c|c|c|c|c|c|c|c|}
\hline & \multicolumn{3}{|c|}{ Bonos retirados } & \multicolumn{3}{|c|}{ Bonos nuevos } & \multirow[b]{2}{*}{ 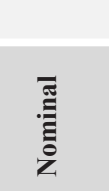 } \\
\hline & 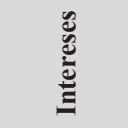 & 递 & 㞼气 & 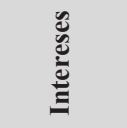 & 这 & 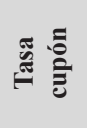 & \\
\hline 2002 & 1.524 .507 & 4 & 8,95 & 1.926 .412 & 4 & 13,65 & 401.905 \\
\hline 2003 & 1.180 .898 & 3 & 11,7 & 1.065 .645 & 3 & 12,9 & -115.254 \\
\hline 2004 & 128.403 & 241 & 9,3 & 162.626 & 241 & 12,6 & 34.224 \\
\hline 2005 & 164.677 & 141 & 11,25 & 173.943 & 141 & 12,07 & 9.266 \\
\hline
\end{tabular}

Fuente: Contraloría General de la República. Informe anual de deuda pública 2005 (16).

A partir de 2006, si bien no se hace pública la información sobre los términos pactados en las operaciones de canje, si sigue expresa la preocupación por los costos cada vez más crecientes, manifestación grabada en cada uno de los informes anuales de la Contraloría.

Hasta este punto se concluye que es innegable que Colombia desde 2002 ha mejorado sus perfiles de deuda y su posición deudora neta debido 
a que ha sabido aprovechar la coyuntura de menores tasas de interés, ritmos más altos de revaluación y abundancia de reservas internacionales, pero no se puede pasar por alto que este es un factor coyuntural y que la gestión de la deuda no puede dejarse a la suerte, ya que el endeudamiento para pagar deuda a costos más altos implica un gran desvío de recursos fiscales desde los sectores que más requieren de la atención estatal.

Una comparación de los gastos financieros del Estado con los gastos de inversión social nos permite aproximarnos al ingente costo de oportunidad que implica no contar con un financiamiento subsidiado del déficit público.

Así, mientras desde 2002 se hace sentir la disminución de las transferencias a Educacióny Salud a raíz de las reformas de la 2001 y 2007 con el argumento de que el "desbordado" crecimiento del gasto en transferencias impiden conseguir el equilibrio fiscal y han conducido los "preocupantes" niveles de déficit con sus nocivas consecuencias en la estabilidad de precios y el balance externo, se ignora por completo que los cargos financieros de la deuda $(4,14 \%$ del PIB de 2009) superan alarmantemente al nivel de gasto social en salud y educación (3,3\% del PIB de 2009). Con los $\$ 17$ billones pagados por intereses se solucionaría la crisis del Sector Salud y se ofrecería una educación de calidad. Este es el verdadero costo que ha llevado la sociedad por mantener la independencia del Banco Central y tranquilizar a las agencias de riesgos.

GRÁFICO 10. SGP SALUD MÁS EDUCACIÓN VS INTERESES DE DEUDA PÚBLICA 1994-2009.

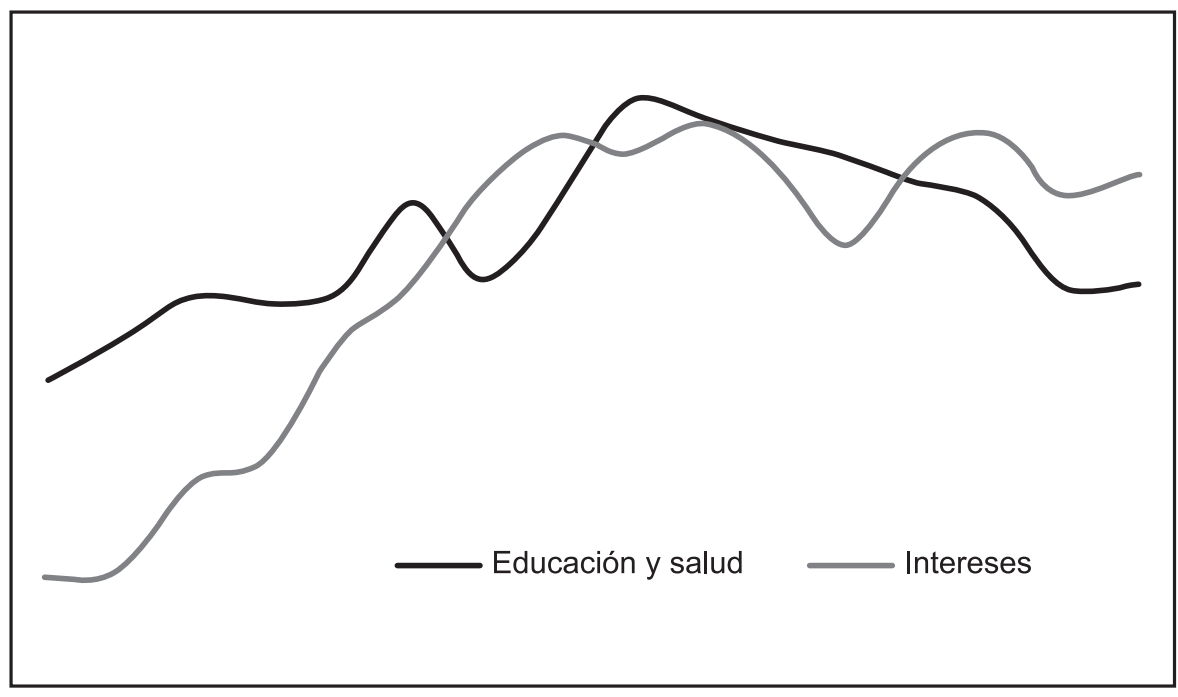

Fuente: Elaboración propia con base en DNP. 


\section{CONCLUSIONES}

El trabajo anterior fue elaborado con la intención de exponer los argumentos teóricos y empíricos necesarios para abrir una reflexión sobre hasta qué punto nos ha convenido y no la renuncia a un instrumento de financiación de bajo costo so pena de no correr el riesgo de incumplir las metas de inflación. Esta reflexión tiene el ánimo de resucitar el debate de la década de los años noventa - abandonado en tiempos recientes- , el cual es necesario ante la pena social por la que atraviesa una mayoría importante de la población Colombia en situación de pobreza.

Las ideas de Keynes sobre los efectos negativos para la demanda agregada de la destacada contra preferencia por la liquidez de las autoridades colombianas, aplicadas al ámbito de la política financiera del Estado, expuestas en la revisión teórica y revisadas a nivel empírico, nos señalan también la necesidad de recapacitar profundamente sobre los fundamentales teóricos de nuestras recetas macroeconómicas.

La eficiencia de una política no se mide sólo por el grado de alcance de un objetivo sino también por los costos que implica su implementación y los efectos colaterales que esta produce, de tal manera que es prematuro afirmar el éxito del régimen de inflación objetivo mediante el control de las tasas de interés de corto plazo en el logro de una política económica creíble que reduzca la incertidumbre de los agentes, mientras no se tengan en cuenta los costos de implementación de dicha política y su inconsistencia con los demás objetivos, en especial cuando el mandato constitucional exige la coordinación de las funciones del Banco Central con la política económica general. Una aproximación a tales costos fue la motivación principal de este trabajo.

La independencia del Banco Central que consagra la reforma institucional de 1991 hace muy difícil el uso moderado de la emisión monetaria, lo cual solo ha encarecido la financiación del gasto público y ha favorecido al capital financiero colombiano, no solo en el sector bancario sino en los Fondos de Pensiones, privilegiados por su posición oligopsónica en la compra de TES.

Se ha demostrado que en los últimos años una parte importante de la expansión monetaria se ha dirigido a incrementar los portafolios de TES en las entidades financieras. Dichos portafolios tuvieron un crecimiento real de 36 por ciento en 2000 y 16 por ciento en 2001, impidiendo que la expansión monetaria se reflejara en un mayor crédito al sector privado. 
Con una moneda parcialmente soberana el Estado tiene cierto espacio para cubrir sus desequilibrios financieros con emisión moderada o préstamos del Banco de la República a tasas inferiores a la DTF. Por ello se hace importante que en el manejo de la deuda pública se evite el excesivo endeudamiento externo, pues se pierde el grado de soberanía de la moneda nacional. Todo lo que pueda adquirirse en el mercado doméstico debe ser financiado en el mercado doméstico y en la moneda nacional. Pero una política de esta naturaleza implica tomar distancia frente a las mitologías actuales de la supuesta independencia del Banco Central y la priorización de la política económica no sólo en términos de inflación o balance fiscal, sino, y tal vez más importante, en términos de crecimiento económico y empleo. Ello implica cambios políticos que todavía no se vislumbran en el horizonte colombiano.

\section{REFERENCIAS BIBLIOGRÁFICAS}

1. Cordero, J. Keynesian Macroeconomics With The LM Relationship. San José de Costa Rica : s.n., 2008.

2. Keynes, John Maynard. Proposal for an international currency union, letter to M. Norman 19 Dec 1941. London : Macmillanforthe Royal Economics Society, 1980, Activities 1940-1944. Shaping the Post-War World: The Clearing Union, Vol. XXV.

3. Tily, Geoff. Keynes's theory of liquidity preference and his debt management and monetary policies. 5, Cambridge : Academic Press, 2006, Cambridge journal Economics, págs. 657-670. 0309-166X.

4. Sicsú, João. Políticas não-monetárias de controle da inflação: uma proposta pós-keynesiana. 39, Revista Análise Econômica, Vol. 21.

5. Keynes, John Maynard. Proposal for an international currency union. London: Macmillanforthe Royal Economics Society, 1980, Vol. XXV, págs. 98-100.

6. Sicsú, Joâo. Uma critica a tese da independência do Banco Central. Rio de Janeiro: Universidade Federal Do Rio de Janeiro.

7. Ramos, Jorge y Rodríguez, Norberto. Déficit fiscal y tasas de interés en Colombia. 19, Bogotá: Banco de la República, 1995, Serie Borradores Semanales de Economía.

8. Hermann, Jennifer. A macroeconomia da divida pública: Notas sobre o debate teórico e a experiência bradileira recente. Río de Janeiro: Universidade Federal de Rio de Janeiro.

9. Cabrera, Mauricio y González, Jorge. La disyuntiva no es pagar o sisar la deuda, es pagarla a sobreprecio o a un precio justo. 3, Bogotá: Universidad Externado de Colombia, 2000, Revista Economía Institucional, Vol. 2. 0124-5996. 
10. El Tiempo. Incertidumbre por baja en el costo del crédito. El Tiempo. 23 de Febrero de 1994.

11. - . La cuadratura del círculo. Diario El Tiempo. 1994.

12. - . Las tasas de interés no bajaran para todos. Diario El Tiempo. 1995.

13. División Técnica de Corredores Asiciados. Descoordinación de políticas fiscales y monetarias. El Tiempo. 15 de Octubre de 1996.

14. Castiblanco, Luis Arley. La deuda publica interna y el manejo de los TES. 288, Bogotá: Contraloría General de la República, 2002, Economía Colombiana. 0120-4998.

15 Hernández, Antonio. Situación de la deuda pública en Colombia - 2004. s.l.: Contraloría General de la República - Informe anual de deuda pública, 2004.

16. Contraloría General de la República - Colombia. www.lib.utexas.edu. www.lib.utexas.edu. [En línea] Junio de 2006. [Citado el: 10 de Agosto de 2011.] http://www.lib.utexas.edu/benson/lagovdocs/colombia/ federal/contraloria/Informe $\% 20$ situacion $\% 20 \mathrm{de} \% 201 \mathrm{l} \% 20 \mathrm{deuda} \% 20$ 2005.pdf.

\section{BIBLIOGRAFÍA RECOMENDADA}

“A subasta los nuevos títulos TES" (1993, febrero 6). Archivo de El Tiempo.

Cabrera, M., González, J. (2002). “El desmanejo de La deuda pública interna". Informe especial-Contraloría General de la República.

Carvalho, Fernando J. (2005). “Uma contribuição ao debate em torno da eficácia da política monetária e algumas implicações para o caso do Brasil". Revista de Economía Política. UFRJ.

“El emisor recogió ayer otros \$78.000 millones". (1993, Agosto 12) Archivo de El Tiempo.

“El emisor suelta otros $\$ 180.000$ millones". (1996, Abril 17). Archivo de El Tiempo.

Echeverry, J.C. (1999). “La recesión actual en Colombia: Flujos, Balances y Política anticíclica". Archivos de Macroeconomía, 113, Departamento Nacional de Planeación.

Easterly, W. (1991). “La Macroeconomía del Déficit del Sector Público: el Caso de Colombia". Ensayos sobre política económica, 20, pp107-144. 
García, J., Guterman, L. (1988). “Medición del déficit del sector público colombiano y su financiación: 1950-1986". Ensayos sobre política económica, 14, p115-133.

Keynes, J. M. 1971D. "A Treatise on Money".Collected Writings, Vol. VI, London, Macmillan for the Royal Economics Society

Marselli, R. (1993). "Treasury financing and bank-lending reserves casuality: The case of Italy, 1975-1990". Journal of Post-Keynesian Economics,15, 4. Pp571-587.

Mendivelso, Nelly (2005) "La deuda pública : una bola de nieve" . UN Periódico, No. 85. Consultado el 25/11/09 en http://unperiodico.unal. edu.co/ediciones/85/03.htm.

Minford, P., Pell, D. (2002). "Advanced Macroeconomics". Northampton, MA.

Lavoie, M.(1992). "Foundations of Post-Keynesian Economics Analysis". Brookfield: Edward Elgar Publishing.

“Problemas del Estrés Financiero". (1996, Enero 15). Archivo de El Tiempo.

Suescún, R.(1992) “Inflación y Devaluación como un fenómeno fiscal: la financiación óptima del gobierno a través de la tributación, el señoreaje y las utilidades por compra venta de divisas". Ensayossobrepolíticaeconómica, 22, pp7-75.

Títulos de Tesorería TES. (n.d.) Ministerio de Hacienda y Crédito Público. Documento del Grupo de Mercado de Capitales Interno.

Wray, R. (1998). “Understanding Modern Money: The Key to Full Employment and PriceStability". Northampton: Edward Elgar Publishing.

Zuccardi, I.E.(2002). “Crecimiento y Ciclos Económicos. Efectos de los Choques de Oferta y Demanda en el crecimiento Colombiano", Archivos de Macroeconomía, 187, Departamento Nacional de Planeación. 
